OPEN ACCESS

Edited by:

Chrishan S. Samuel,

Monash University, Australia

Reviewed by:

Michael A. Hill,

University of Missouri, USA

Sai Wang Seto,

National Institute of Complementary

Medicine, Australia

*Correspondence:

Asad Zeidan

asad.zeidan@aub.edu.Ib

†These authors have contributed

equally to this work.

Specialty section:

This article was submitted to Cardiovascular and Smooth Muscle

Pharmacology,

a section of the journal

Frontiers in Pharmacology

Received: 16 December 2015

Accepted: 16 March 2016

Published: 07 April 2016

Citation:

Nour-Eldine W, Ghantous CM

Zibara K, Dib L, Issaa H, Itani HA,

El-Zein N and Zeidan A (2016)

Adiponectin Attenuates Angiotensin

II-Induced Vascular Smooth Muscle Cell Remodeling through Nitric Oxide and the RhoA/ROCK Pathway.

Front. Pharmacol. 7:86.

doi: 10.3389/fphar.2016.00086

\section{Adiponectin Attenuates Angiotensin II-Induced Vascular Smooth Muscle Cell Remodeling through Nitric Oxide and the RhoA/ROCK Pathway}

\author{
Wared Nour-Eldine ${ }^{1,2+}$, Crystal M. Ghantous ${ }^{11}$, Kazem Zibara ${ }^{2}$, Leila Dib ${ }^{1}$, \\ Hawraa Issaa ${ }^{1,2}$, Hana A. Itani ${ }^{3}$, Nabil El-Zein ${ }^{2}$ and Asad Zeidan ${ }^{1 *}$ \\ ' Cardiovascular Physiology Lab, Department of Anatomy, Cell Biology and Physiology, Faculty of Medicine, American \\ University of Beirut, Beirut, Lebanon, ${ }^{2}$ ERO45, Laboratory of Stem Cells, Department of Biology, Faculty of Sciences, The \\ Lebanese University, Beirut, Lebanon, ${ }^{3}$ Division of Clinical Pharmacology, Department of Medicine, Vanderbilt University \\ School of Medicine, Nashville, TN, USA
}

Introduction: Adiponectin (APN), an adipocytokine, exerts protective effects on cardiac remodeling, while angiotensin II (Ang II) induces hypertension and vascular remodeling. The potential protective role of APN on the vasculature during hypertension has not been fully elucidated yet. Here, we evaluate the molecular mechanisms of the protective role of APN in the physiological response of the vascular wall to Ang II.

Methods and Results: Rat aortic tissues were used to investigate the effect of APN on Ang II-induced vascular remodeling and hypertrophy. We investigated whether nitric oxide (NO), the RhoA/ROCK pathway, actin cytoskeleton remodeling, and reactive oxygen species (ROS) mediate the anti-hypertrophic effect of APN. Ang II-induced protein synthesis was attenuated by pre-treatment with APN, NO donor S-nitroso$\mathrm{N}$-acetylpenicillamine (SNAP), or cGMP. The hypertrophic response to Ang II was associated with a significant increase in RhoA activation and vascular force production, which were prevented by APN and SNAP. NO was also associated with inhibition of Ang II-induced phosphorylation of cofilin. In addition, immunohistochemistry revealed that $24 \mathrm{~h}$ Ang II treatment increased the F- to G-actin ratio, an effect that was inhibited by SNAP. Ang II-induced ROS formation and upregulation of $\mathrm{p} 22^{\text {phox }}$ mRNA expression were inhibited by APN and NO. Both compounds failed to inhibit Nox 1 and p47phox expression.

Conclusion: Our results suggest that the anti-hypertrophic effects of APN are due, in part, to NO-dependent inhibition of the RhoA/ROCK pathway and ROS formation.

Keywords: adiponectin, angiotensin II, nitric oxide, VSMC, remodeling

\section{INTRODUCTION}

Hypertension is a primary risk factor for other cardiovascular diseases, such as myocardial infarction, cardiac hypertrophy, heart failure, atherosclerosis, and vascular hypertrophy (Zeidan et al., 2003; Zhang et al., 2005; Pedrinelli et al., 2012). These diseases are governed by structural and functional changes in the cardiovascular system. Angiotensin II (Ang II) is a potent vasoconstrictor 
that binds to its angiotensin receptor $\left(\mathrm{AT}_{1}\right)$ in different organ systems to increase blood pressure. In the vascular system, Ang II binds to $\mathrm{AT}_{1}$ receptors to induce vascular smooth muscle cell (VSMC) contraction and subsequent vasoconstriction (Bagi et al., 2011). Moreover, Ang II promotes VSMC remodeling, cell growth, fibrosis, collagen deposition, and contractility (Touyz, 2005; Heeneman et al., 2007).

The molecular mechanisms associated with VSMC growth and contraction include reactive oxygen species (ROS) formation and the activation of several signaling pathways, such as MAPK and the RhoA/ROCK pathway (Zeidan et al., 2007). The RhoA/ROCK pathway is activated by several hypertensionassociated factors, such as the Ang II (Carbone et al., 2015), endothelin-1 (Et-1; Homma et al., 2007), leptin (Zeidan et al., 2007), and mechanical stretch (Zeidan et al., 2003). Activation of the RhoA/ROCK pathway leads to the phosphorylation and subsequent inhibition of the actin-depolymerization enzyme cofilin, and thus promotes formation of stress fibers, an increase in F-actin formation, and depletion in G-actin (Zeidan et al., 2007). Hence, the RhoA/ROCK pathway affects cell morphology, produces modifications in actin cytoskeleton, and regulates transcription factors leading to cellular hypertrophy (Zeidan et al., 2006).

Nitric oxide (NO) exerts a protective role on cardiovascular function (Jones and Bolli, 2006). Activation of endothelial nitric oxide synthase (eNOS) produces NO, which exerts vasoprotective effects on the vascular wall by maintaining vasodilation, anticoagulation, and anti-oxidation (Zhou et al., 2004). Moreover, NO primarily mediates endothelium-dependent relaxation through activation of soluble guanylyl cyclase, leading to an increased production of cGMP which, in turn, activates several phosphodiesterases and cGMP-dependent protein kinases (Mayer et al., 1998). However, the precise mechanisms by which NO prevents vascular pathology are not well understood.

Evidence suggests that the hypertrophic signaling pathways triggered in response to Ang II are mediated by ROS formation (Dai et al., 2011). The enhanced production of ROS increases free radicles and leads to oxidative stress, which in turn induces vascular dysfunction and remodeling (Touyz and Briones, 2011; Montezano and Touyz, 2012). ROS is produced by a multisubunit complex protein called NADPH oxidase, which consists of several membrane-bound proteins/components including Nox1, Nox4, p22 $2^{\text {phox }}$ and cytosolic components including Rac1 and $47^{\text {phox }}$. Many studies have shown the important role of p $22^{\text {phox }}$ and $\mathrm{p} 47^{\text {phox }}$ in Nox1 activation in VSMC (Ushio-Fukai et al., 1996; Lavigne et al., 2001; Van Heerebeek et al., 2002). Moreover, studies have shown the involvement of $\mathrm{p} 22^{\mathrm{phox}}$ in different agonists-induced ROS formation, including Ang II (Ushio-Fukai et al., 1996).

Adiponectin (APN) is a circulating adipokine that plays a protective role in the cardiovascular system (Caselli et al., 2014). It exerts potent anti-atherosclerotic, anti-inflammatory, and antidiabetic effects (Shibata et al., 2005; Tajtakova et al., 2010). Plasma APN levels negatively correlate with cardiovascular disease, such as hypertension and metabolic disorders (Zhu et al., 2008). Physiological concentrations of APN range between 5 and $25 \mu \mathrm{g} / \mathrm{mL}$ (Ouchi et al., 1999) and are significantly reduced in hypertensive patients (Kim et al., 2013). This reduction in adiponectin is believed to be responsible for hypertensionassociated cardiovascular diseases (Menzaghi et al., 2007; Kawai et al., 2013). Several studies have investigated the relationship between Ang II and adiponectin (Uchida et al., 2008; Ohashi et al., 2011). It has been shown that adiponectin has the ability to protect against Ang II-induced cardiac fibrosis (Fujita et al., 2008) and prevent Ang II-induced apoptosis in human endothelial cells (Lin et al., 2004). Furthermore, APN expression ameliorates the development of hypertension in APN-deficient mice and hypertensive KKAy mice (Ohashi et al., 2006). Uchida et al. (2008) have shown that Ang II infusion decreased plasma adiponectin levels via angiotensin receptor-1. Moreover, renin angiotensin system inhibition was associated with increased plasma adiponectin levels (Uchida et al., 2008).

Adiponectin is secreted predominantly by adipose tissue (reviewed in Ghantous et al., 2015a), but several studies have shown the ability of different tissues to produce APN (reviewed in Ghantous et al., 2015a). Although, many investigations have tried to uncover the molecular mechanisms responsible for the cardioprotective effects of APN, the various signaling mechanisms in VSMC remain unclear. In this study, we examined whether APN exerts protective effects against Ang II-induced vascular hypertrophy. Moreover, we investigated the possible role of NO, ROS, RhoA/ROCK pathway, and actin cytoskeleton dynamics.

\section{MATERIALS AND METHODS}

\section{Rat Aorta Organ Culture}

Male Sprague-Dawley rats (200-250 g) were killed by $\mathrm{CO}_{2}$, as approved by the Animal Ethics Committee, American University of Beirut. The thoracic aorta was isolated and stripped of the surrounding adipose and connective tissue using $N$-HEPES buffer solution (400 mmol/L NaCl, $200 \mathrm{mmol} / \mathrm{L} \mathrm{KCl,} 100 \mathrm{mmol} / \mathrm{L}$ $\mathrm{MgCl}_{2}, 100 \mathrm{mmol} / \mathrm{L}$ HEPES, $11.5 \mathrm{mmol} / \mathrm{L}$ glucose) in 5\% penicillin-streptomycin. Aortic rings were then transferred to DMEM/F-12 HAM culture media and incubated at $37^{\circ} \mathrm{C}, 5 \%$ $\mathrm{CO}_{2}$. Different inhibitors and agonists were added to the media $1 \mathrm{~h}$ before adding Ang II $(1 \mu \mathrm{mol} / \mathrm{L}$; Sigma-Aldrich, St. Louis, MO, USA) as follows: actin depolymerizing agent Cytochalasin D (Cyt-D, $1 \mu \mathrm{mol} / \mathrm{L}$, Sigma-Aldrich, St. Louis, $\mathrm{MO}$, USA), the $\mathrm{NO}$ donor $S$-nitroso- $N$-acetylpenicillamine (SNAP, $0.1 \mathrm{mmol} / \mathrm{L}$, Sigma-Aldrich, St. Louis, MO, USA), the cGMP analog 8-Bromo-cGMP (cGMP, $100 \mu \mathrm{mol} / \mathrm{L}$, Santa Cruz Biotechnology, Santa Cruz, CA, USA), the specific inhibitor of cGMP-dependent protein kinase Rp-8-Br-PET-cGMPS (cGMPS, $50 \mathrm{nmol} / \mathrm{L}$, Santa Cruz Biotechnology, Santa Cruz, CA, USA), adiponectin ( $5 \mu \mathrm{g} / \mathrm{ml}$, Santa Cruz Biotechnology, Santa Cruz, CA, USA), and NG-nitro-L-arginine methyl ester (LNAME; $2 \mathrm{mmol} / \mathrm{L}$, Sigma-Aldrich, St. Louis, MO, USA). The concentrations of Ang II and all pre-treatments used in this study were determined in preliminary studies to avoid cytotoxicity while still maintaining effectiveness. Following incubation, aortic rings were SNAP-frozen in liquid nitrogen and stored. 


\section{Measurement of Leucine Incorporation}

Protein synthesis was examined by analysis of $\left[{ }^{3} \mathrm{H}\right]$-leucine incorporation. Endothelium-intact and denuded aortic rings were cultured with or without inhibitors for $24 \mathrm{~h}$ and with $\left[{ }^{3} \mathrm{H}\right]$-leucine in order to measure protein synthesis as described previously (Zeidan et al., 2003).

\section{Vascular Function Studies}

The thoracic aorta rings were placed immediately in ice-cold HEPES-buffer solution. The composition of the HEPES-buffer solution was in mmol/L: $\mathrm{NaCl} 135.5, \mathrm{KCl} 5.9, \mathrm{CaCl}_{2} 2.5$, $\mathrm{MgCl}_{2}$ 1.2, glucose 11.6, HEPES 11.6, $\mathrm{pH}=7.4$. High- $\mathrm{K}^{+}$ solution $(60 \mathrm{mmol} / \mathrm{L})$ was obtained by isomolar exchange of $\mathrm{NaCl}$ for $\mathrm{KCl}$. Aortic rings were cultured with/without Ang II $(1 \mu \mathrm{mol} / \mathrm{L})$ for $24 \mathrm{~h}$ and pre-treated with/without adiponectin $(5 \mu \mathrm{g} / \mathrm{ml})$, the NO donor SNAP $(0.1 \mathrm{mmol} / \mathrm{L}), 8$-Br-cGMP (cGMP; $100 \mu \mathrm{mol} / \mathrm{L}$ ), the specific inhibitor of cGMP-dependent protein kinase Rp-8-Br-PET-cGMPS (cGMPS, $50 \mathrm{nmol} / \mathrm{L}$ ), or L-NAME $(2 \mathrm{mmol} / \mathrm{L})$. After that, cultured rat aortic segments were washed and mounted in a myograph $(620 \mathrm{M}$, Danish Myo Technology, Aarhus, Denmark) and equilibrated at a resting tension of $2 \mathrm{~g}$ for $45 \mathrm{~min}$. The resting tension was readjusted every 15 min during equilibration time before starting the experiments. After resting tension of each aortic ring have stabilized, maximum isometric contraction was measured after addition of high- $\mathrm{K}^{+}$. After that, the aortic rings were pre-contracted with $1 \mu \mathrm{mol} / \mathrm{L}$ phenylephrine (PE). When the plateau was reached, a single concentration of $1 \mu \mathrm{mol} / \mathrm{L}$ acetylcholine $(\mathrm{ACh})$ was added to evaluate endothelium functional integrity of the aortic rings (Furchgott, 1983). The aortic ring was discarded if relaxation with ACh was equal to or lower than $80 \%$ of the maximal contraction obtained in aortic rings pre-contracted with PE. The inability of $1 \mu \mathrm{M}$ ACh to induce muscle relaxation in the denuded aortic ring indicated the removal of endothelial cells. Contractile responses to $1 \mu \mathrm{mol} / \mathrm{L} \mathrm{PE}$ and subsequent relaxing responses to $0.1 \mathrm{mmol} / \mathrm{L}$ sodium nitroprusside were also compared in aortic ring with or without endothelium to ensure that the VSMC was not damaged during removal of the endothelium. Results in isometric contractions were recorded using $620 \mathrm{M}$ myograph connected to a PowerLab $4 / 35$ data acquisition system (AD Instruments, Sydney, NSW, Australia) and saved in a computer. Results were expressed as $\mathrm{mN} / \mathrm{mm}$.

\section{Protein Extraction and Western Blotting}

Treated aortic rings were transferred to liquid nitrogen and homogenized in order to extract proteins. The rings were added to $300 \mu \mathrm{L}$ lysis buffer $(50 \mathrm{mmol} / \mathrm{L}$ Tris, $\mathrm{pH}=8.0,150 \mathrm{mmol} / \mathrm{L}$ $\mathrm{NaCl}, 1 \%$ Nonidet-P $40,0.5 \%$ sodium deoxycholate) with protease inhibitors. They were centrifuged at $9,000 \mathrm{rpm}$ for $5 \mathrm{~min}$ at $4^{\circ} \mathrm{C}$. The supernatant protein solution was then aspirated and quantified using Bradford assay. Equal amounts of extracted proteins were then loaded on a $12 \%$ SDS-PAGE and transferred to a nitrocellulose membrane. Blots were then probed with specific antibodies, at 1:1000 dilution in 5\% BSA, against RhoA, p-cofilin, and actin (Sigma-Aldrich, St. Louis, MO, USA). Proteins were detected using ECL immunoblotting detection system (Santa Cruz Biotechnology, Santa Cruz, CA, USA). The Western blot images were acquired using a ChemiDoc MP System and Image Lab software, followed by quantification of the blots using ImageJ software.

\section{RNA Isolation and Real-Time PCR}

Ribonucleic acid (RNA) was isolated from control or treated aortic rings and Real-Time PCR was done as previously described. The primers were: Nox1 forward $5^{\prime}$-TTTCCTAAACT ACCGACTC- $3^{\prime}$ and Nox1 reverse $5^{\prime}$-GTGCGACAACGGA CTATC- $3^{\prime}$, p2 $2^{\text {phox }}$ forward 5'-TGGCCTGATCCTCATCACAG$3^{\prime}$ and $\mathrm{p} 22^{\text {phox }}$ reverse $5^{\prime}$-AGGCACGGACAGCAGTAAGT- $3^{\prime}$, p $47^{\text {phox }}$ forward $5^{\prime}$-GCTGCCCACACCTCTTGAACTT- $3^{\prime}$ and p47 $7^{\text {phox }}$ reverse $5^{\prime}$-TCTTCAGGCAAAACCACCA-3', and $18 \mathrm{~S}$ rRNA forward $5^{\prime}$-GTAACCCGTTGAACCCCATT- $3^{\prime}$ and $18 \mathrm{~S}$ rRNA reverse 5'-CCATCCAATCGGTAGTAGCG-3' which was used as the housekeeping gene to normalize expression.

\section{Analysis of RhoA Activity}

To assess the effect of Ang II on RhoA activity in aortic rings, we measured the level of RhoA-GTP using the RhoA G-LISA Activation Assay Kit as per the manufacturer's instructions (Cytoskeleton, Denver, CO, USA).

\section{Measurement of RhoA Translocation by Western Blot}

Tissue lysates obtained after homogenization were collected in a homogenization buffer $(\mathrm{pH}=7.5)$ containing $2 \mathrm{mmol} / \mathrm{L}$ Tris, $1 \mathrm{mmol} / \mathrm{L}$ DTT, $2 \mathrm{mmol} / \mathrm{L}$ EDTA, $2 \mathrm{mmol} / \mathrm{L}$ EGTA, $50 \mathrm{mmol} / \mathrm{L} \mathrm{NaF}, 0.2 \mathrm{mmol} / \mathrm{L} \mathrm{Na}_{3} \mathrm{VO}_{4}$ and protease inhibitor cocktail. The homogenate was then sheared using a $26 \mathrm{G}$ needle and pelleted by a $10 \mathrm{~min}$ centrifugation at $5,000 \mathrm{rpm}$ at $4^{\circ} \mathrm{C}$. The supernatant was further centrifuged at $57,000 \mathrm{rpm}$ for $60 \mathrm{~min}$ at $4^{\circ} \mathrm{C}$ and the resulting supernatant was the cytosolic fraction. The pellet was re-homogenized in lysis buffer $(\mathrm{pH}=7.5)$ containing $50 \mathrm{mmol} / \mathrm{L}$ Tris, $150 \mathrm{mmol} / \mathrm{L} \mathrm{NaCl}$, $2 \mathrm{mmol} / \mathrm{L}$ EDTA, $2 \mathrm{mmol} / \mathrm{L}$ EGTA, $50 \mathrm{mmol} / \mathrm{L} \mathrm{NaF}, 0.2 \mathrm{mmol} / \mathrm{L}$ $\mathrm{Na}_{3} \mathrm{VO}_{4}, 10 \mathrm{mmol} / \mathrm{L} \mathrm{Na} 4 \mathrm{PO} 7,40 \mathrm{mmol} / \mathrm{L}$ B-glycero-phosphate, $1 \%$ Triton X-100, 10\% glycerol, and protease inhibitor cocktail. The resulting homogenate was the membrane fraction. Both fractions, cytosolic $(12 \mu \mathrm{g})$ and membrane $(25 \mu \mathrm{g})$ were then blotted with anti-RhoA antibody (Santa Cruz Biotechnology, Santa Cruz, CA, USA), as previously explained (Zeidan et al., 2007).

\section{Measurement of F/G Actin Ratio by Western Blot}

Aortic rings were homogenized and added to lysis buffer $\left(50 \mathrm{mmol} / \mathrm{L}\right.$ PIPES, $50 \mathrm{mmol} / \mathrm{L} \mathrm{NaCl}, 5 \mathrm{mmol} / \mathrm{L} \mathrm{MgCl}_{2}$, $5 \mathrm{mmol} / \mathrm{L}$ EGTA, 5\% glycerol, $0.1 \%$ Nonidet-P40, $0.1 \%$ Triton X-100, $0.1 \%$ Tween $20,0.1 \% \quad \beta$-mercaptoethanol, $1 \mathrm{mmol} / \mathrm{L}$ ATP, 1:100 protease inhibitor). The homogenate was then sheared using a $26 \mathrm{G}$ needle and centrifuged at $2,000 \mathrm{rpm}$ for $5 \mathrm{~min}$ at $37^{\circ} \mathrm{C}$. The resulting supernatant was removed and then ultra-centrifuged at $100,000 \mathrm{~g}$ for $1 \mathrm{~h}$ 
at $37^{\circ} \mathrm{C}$ in order to separate the F-actin from the G-actin, present in the pellet and the supernatant respectively. The supernatant was removed and ready to use, while the pellet was re-suspended using Cytochalasin D (10 $\mu \mathrm{mol} / \mathrm{L})$ which depolymerizes F-actin into G-actin. The solution was then incubated on ice for $1 \mathrm{~h}$ and suspended up and down every 15 min. After the addition of Laemmli, resulting G- and F-actin samples were denatured by heat then loaded on a $12 \%$ acrylamide gel and the membrane blotted with antiactin antibody (Cell Signaling Technology, Danvers, MA, USA).

\section{Immunohistochemistry of RhoA Translocation}

Frozen aorta tissue sections were fixed in $4 \%$ paraformaldehyde for $15 \mathrm{~min}$ at room temperature, then rinsed twice with PBS, and permeabilized with $0.2 \%$ Triton X-100 for 20 min. Blocking was done for $1 \mathrm{~h}$ with a blocking solution consisting of $1 \%$ BSA and $0.1 \%$ Triton X-100 in PBS. Sections were then incubated overnight with anti-RhoA primary antibody at 1:100 dilution in $1 \%$ BSA and $0.05 \%$ Tween-20, then rinsed twice with $0.1 \%$ Tween-20. A goat anti-rabbit secondary antibody, conjugated to Alexa Fluor (AF594 IgG, Invitrogen, USA), was then added at $1: 250$ dilution in $1 \%$ BSA and $0.05 \%$ Tween-20 for $1 \mathrm{~h}$ in the dark. Slides were then rinsed five times in $0.1 \%$ Tween20 at 10 min intervals. The nuclear stain 4',6-diamidino-2phenylindole (DAPI) was used at 1:5000 dilution and sections were incubated for $20 \mathrm{~min}$ in the dark. Imaging was done using a LSM710 laser confocal microscopy (Zeiss, Germany).

\section{Immunohistochemistry of F/G-Actin}

After different treatments, blood vessels were sliced crosssectionally into frozen sections of $4 \mu \mathrm{m}$ thickness and fixed in $4 \%$ formaldehyde, $0.2 \%$ Triton X-100 in the PEM cytoskeleton stabilizing buffer $(100 \mathrm{mmol} / \mathrm{L}$ PIPES, $5 \mathrm{mmol} / \mathrm{L}$ EGTA, $2 \mathrm{mmol} / \mathrm{L} \mathrm{MgCl}_{2}, \mathrm{pH}=6.9$ ) for $20 \mathrm{~min}$ at room temperature. They were then rinsed twice in PBS for a few seconds and permeabilized with $0.2 \%$ Triton X-100 in PBS for $15 \mathrm{~min}$. Thereafter, sections were blocked with blocking solution ( $1 \%$ BSA and $0.1 \%$ Triton X-100 in PBS) for $10 \mathrm{~min}$ and washed with PBS, followed by incubation with $100 \mathrm{nmol} / \mathrm{L}$ red fluorescent F-actin stain (Actinstain 555 phalloidin, Cytoskeleton, Denver, CO, USA) and $300 \mathrm{nmol} / \mathrm{L}$ green fluorescent G-actin stain (Deoxyribonuclease I Alexa fluor-488 conjugate, Molecular Probes, USA) in blocking buffer for $20 \mathrm{~min}$ at room temperature in the dark. Confocal images of F-actin and G-actin were captured simultaneously with a fluorescence microscope Zeiss LSM710 (Zeiss, Germany).

\section{Reactive Oxygen Species Analysis}

Following treatment, aorta were cross-sectionally sliced $(4 \mu \mathrm{m}$ thickness) and then stained with DHE dye conjugated to Alexa Fluor 594 (Sigma-Aldrich, St. Louis, MO, USA) at a concentration of $10 \mu \mathrm{mol} / \mathrm{L}$ in $N$-HEPES buffer and placed for $30 \mathrm{~min}$ at $37^{\circ} \mathrm{C}, 5 \% \mathrm{CO}_{2}$. Mounting dye containing DAPI was added to the sections to stain the nuclei. Images were acquired using LSM710 (Zeiss, Germany).

\section{Drugs}

$S$-nitroso- $N$-acetylpenicillamine was prepared as stock solution in DMSO and diluted in the N-HEPES buffer solution. L-NAME, Cyt-D, APN, cGMP, cGMPS were directly dissolved in the $N$-HEPES buffer solution.

Control groups received same concentrations of vehicles (diluted DMSO or N-HEPES buffer).

\section{Statistical Analysis}

Values are presented as mean \pm standard error of the mean (SEM). Data were analyzed using one-way analysis of variance (ANOVA) or $t$-test. Significance was established by Tukey or Holm-Sidak methods. $p<0.05$ was considered to represent significant differences.

\section{RESULTS}

\section{The Effect of Adiponectin on Ang II-Induced Protein Synthesis is Nitric Oxide-Dependent}

We investigated whether a physiological concentration of adiponectin (5 $\mu \mathrm{g} / \mathrm{ml}$; Ouchi et al., 1999) had an antihypertrophic effect on Ang II-induced protein synthesis in VSMC. Endothelium-intact and denuded aortic rings were treated with Ang II ( $1 \mu \mathrm{mol} / \mathrm{L}$; Coles et al., 2007) for $24 \mathrm{~h}$ with $\left[{ }^{3} \mathrm{H}\right]$-leucine in order to study the effect of Ang II on protein synthesis. In control aortic rings, which were not exposed to Ang II, only weak protein synthesis was observed (Figure 1A). Both endothelium-intact and denuded aortic tissue exposed to Ang II exhibited a significant increase in protein synthesis by $190 \pm 21 \%$ (Figure 1A) and $180 \pm 16 \%$ respectively. Pre-treatment of aortic rings with adiponectin $(5 \mu \mathrm{g} / \mathrm{ml})$ for $1 \mathrm{~h}$ and then co-incubated with $1 \mu \mathrm{mol} / \mathrm{L}$ Ang II significantly inhibited Ang II-induced protein synthesis in endothelium-intact (127 $\pm 19 \%$; Figure 1A) and denuded aortic tissue $(118 \pm 11 \%)$.

Moreover, we determined whether inhibition of either NO generation by L-NAME ( $2 \mathrm{mmol} / \mathrm{L}$; Day et al., 1999) or cGMP by the specific inhibitor of cGMP-dependent protein kinase Rp-8-Br-PET-cGMPS (cGMPS, $50 \mathrm{nmol} / \mathrm{L}$ ) prevented the inhibitory effect of adiponectin on Ang II-induced protein synthesis in endothelium-intact aortic rings. Both compounds strongly inhibited the anti-hypertrophic action of adiponectin (Figure 1A) to almost the control level. These data suggest the possible role of NO synthesis and cGMP in the antihypertrophic effect of adiponectin against Ang II-induced protein synthesis.

\section{NO/cGMP Activation Attenuates Ang II-Induced Hypertrophy}

We tested the hypothesis that the NO/cGMP pathway attenuates Ang II-induced protein synthesis in the endothelium-intact aortic ring. We studied the effect of the NO-donor SNAP 

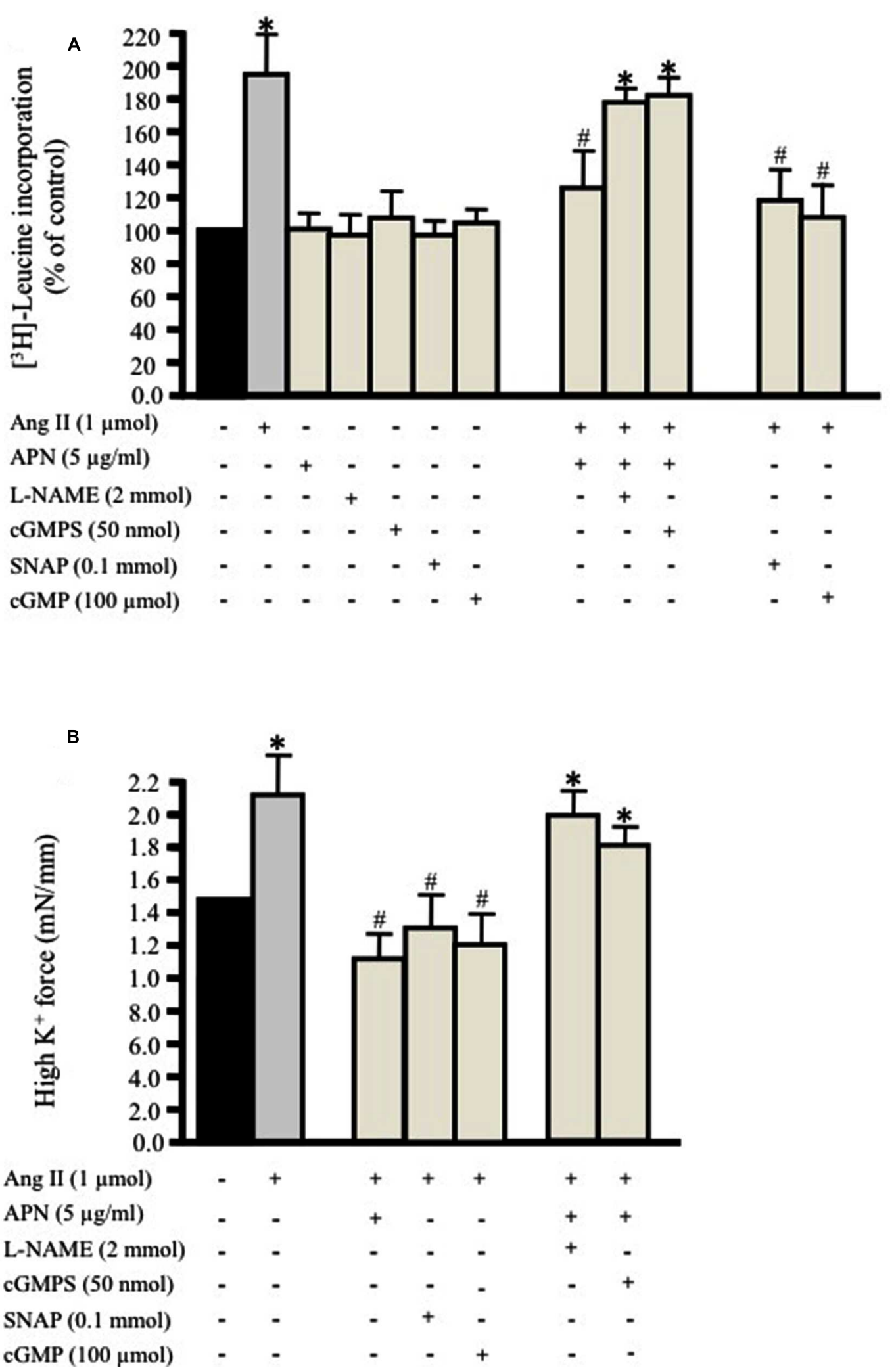

FIGURE 1 | Adiponectin inhibits Ang II-induced protein synthesis and force production in rat aortic ring. Serum-starved endothelium-intact rat aortic rings were pre-treated with adiponectin $(5 \mathrm{\mu g} / \mathrm{ml})$, L-NAME (2 mmol/L), cGMPS (50 nmol/L), S-nitroso-N-acetylpenicillamine (SNAP; $0.1 \mathrm{mmol} / \mathrm{L}), 8$-Br-cGMP (cGMP;

$100 \mu \mathrm{mol} / \mathrm{L}$ ) for $1 \mathrm{~h}$ prior to $24 \mathrm{~h}$ treatment with $1 \mu \mathrm{mol} / \mathrm{L}$ Ang II. [ $\left.{ }^{3} \mathrm{H}\right]$-leucine incorporation is shown in (A). Active stress in response to high $\mathrm{K}^{+}$is shown in (B). Data are shown as mean \pm SEM with $n=5-6$ for all groups. ${ }^{*} p<0.05$ vs. without Ang II (control); \#p $<0.05$ vs. with Ang II. 
(0.1 $\mathrm{mmol} / \mathrm{L}$ ) or the cGMP analog 8-Bromo-cGMP (cGMP, $100 \mu \mathrm{mol} / \mathrm{L}$; Hofbauer et al., 2002) on Ang II-induced protein synthesis in aortic rings cultured for $24 \mathrm{~h}$. Pre-treating the endothelium-intact aortic rings with either the $\mathrm{NO}$ donor SNAP $(0.1 \mathrm{mmol} / \mathrm{L})$ or 8 -Br-cGMP $(100 \mu \mathrm{mol} / \mathrm{L})$ significantly attenuated Ang II-induced vascular hypertrophy (Figure 1A). The inhibition of Ang II-induced protein synthesis caused by SNAP was reversible. Re-culturing the aortic tissue in new media containing Ang II for $24 \mathrm{~h}$ made the total protein synthesis return to control levels.

\section{Adiponectin, NO, and cGMP Decrease Vascular Contractility}

We then examined the impact of pre-treating the aortic ring with adiponectin $(5 \mu \mathrm{g} / \mathrm{ml})$, SNAP $(0.1 \mathrm{mmol} / \mathrm{L})$, or cGMP $(100 \mu \mathrm{mol} / \mathrm{L})$ followed by treatment with Ang II $(1 \mu \mathrm{mol} / \mathrm{L})$ for $24 \mathrm{~h}$ on high $\mathrm{K}^{+}$-induced vascular contractility. The force of aortic rings was normalized to cross-sectional area in order to have active stress. Figure 1B shows that the aortic rings cultured for $24 \mathrm{~h}$ with Ang II alone had greater active stress during high- $\mathrm{K}^{+}$stimulation at optimal length compared to pre-treated aortic rings with adiponectin, SNAP, or cGMP. On other hand, pre-treating the aortic ring with L-NAME ( $2 \mathrm{mmol} / \mathrm{L})$ or Rp-8Br-PET-cGMPS (cGMPS, $50 \mathrm{nmol} / \mathrm{L}$ ) for $1 \mathrm{~h}$ followed by Ang II $(1 \mu \mathrm{mol} / \mathrm{L})$ for $24 \mathrm{~h}$ significantly decreased VSMC contractility induced by high $\mathrm{K}^{+}$(Figure 1B).

\section{Adiponectin Attenuates Ang II-Induced RhoA Activation}

The critical role of RhoA activation has been shown in vascular hypertrophy and contractility induced by several factors, including Ang II (Yamakawa et al., 2000; Molkentin and Dorn, 2001). Our aim was to study the effect of adiponectin on AngII-induced RhoA activation. Figure 2A shows that exposure of aortic rings to $1 \mu \mathrm{mol} / \mathrm{L}$ Ang II caused a time-dependent increase in RhoA activation, which was evident after $5 \mathrm{~min}$

A

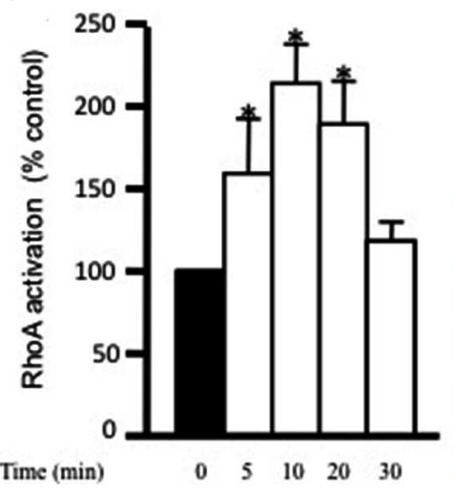

C

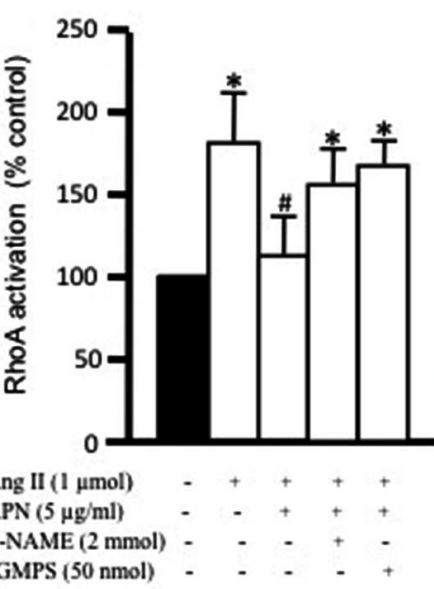

B
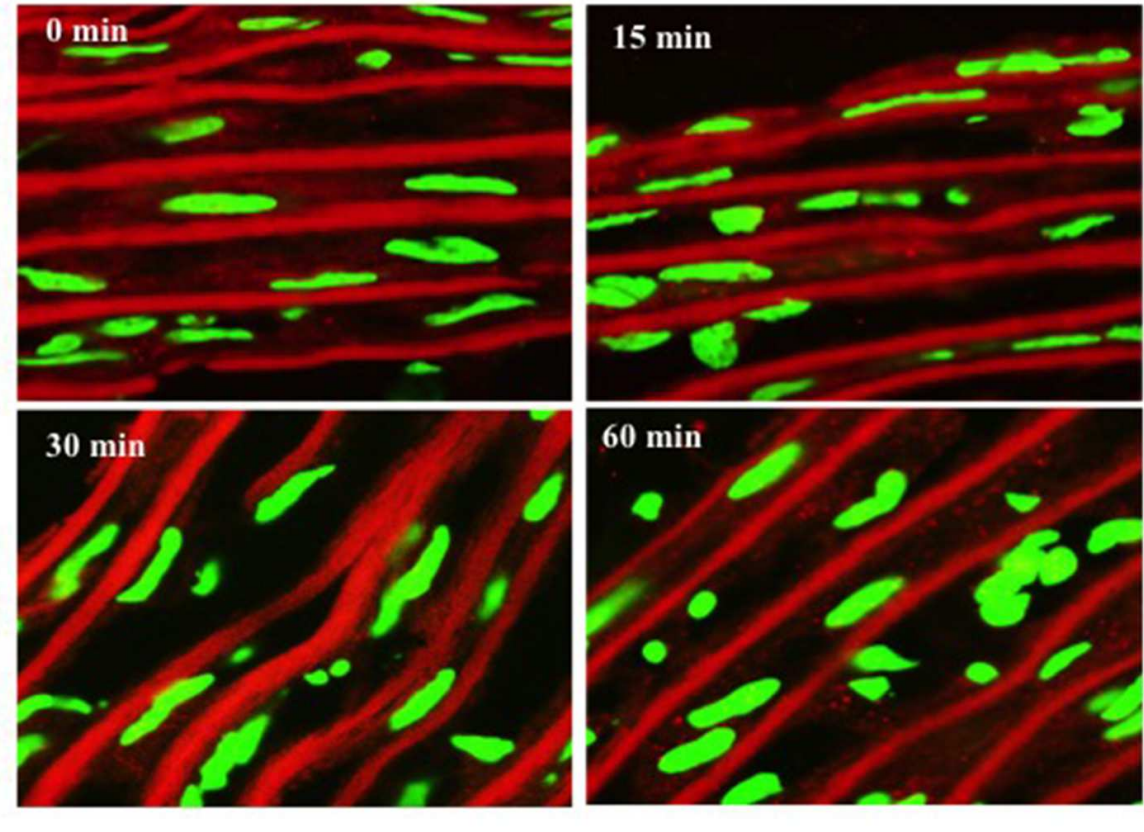

$\begin{array}{llllll}\text { Ang II }(1 \mu \mathrm{mol}) & - & + & + & + & + \\ \text { APN }(5 \mu \mathrm{g} / \mathrm{ml}) & - & - & + & + & + \\ \text { L-NAME }(2 \mathrm{mmol}) & - & - & - & + & - \\ \text { CGMPS }(50 \mathrm{nmol}) & - & - & - & - & +\end{array}$

FIGURE 2 | Adiponectin inhibition of Ang II-induced RhoA activation is NO-dependent. (A) Endothelium-intact rat aortic rings were treated for various times $(0,15,30$, and $60 \mathrm{~min})$ with $1 \mu \mathrm{mol} / \mathrm{L}$ Ang $\mathrm{II}$ and RhoA activation was analyzed with G-LISA kit BK121. (B) Time course of Ang II-induced RhoA translocation. Confocal images for aortic frozen sections at different time points (0, 15, 30, 60 min) stained with DAPI (green) and anti-RhoA antibody (red). (C) Endothelium-intact rat aortic rings were treated for $10 \mathrm{~min}$ with $1 \mu \mathrm{mol} / \mathrm{L}$ Ang $\|$ in the presence or absence of adiponectin (5 $\mu \mathrm{g} / \mathrm{ml}), \mathrm{L}-\mathrm{NAME}(2 \mathrm{mmol} / \mathrm{L})$, cGMPS (50 $\mathrm{nmol} / \mathrm{L})$. RhoA activation was analyzed with G-LISA kit BK121. Data are shown as mean \pm SEM and indicate fold change relative to untreated aortic ring (control). $n=6-7$; ${ }^{*} p<0.05$ vs. without Ang II. 
and peaked at $10 \mathrm{~min}$. There appeared to be a decline in RhoA activity with Ang II treatment for a long duration. To determine whether Ang II-induced RhoA activation in the aorta was associated with cytosolic RhoA translocation to membrane, we investigated RhoA translocation in aortic rings using immunohistochemistry. Figure 2B shows that Ang II treatment for 30 min noticeably induced RhoA translocation from the cytosol to the cell membrane, further indicating RhoA activation.

We then examined whether the anti-hypertrophic effect of adiponectin was mediated via inhibition of RhoA activation. Endothelium-intact aortic rings were pre-treated with adiponectin for $1 \mathrm{~h}$ followed by Ang II treatment for $10 \mathrm{~min}$, the peak of Ang II-induced RhoA activation. Figure 2C shows that adiponectin $(5 \mu \mathrm{g} / \mathrm{ml})$ significantly inhibited Ang II-induced RhoA activation. The inhibitory effect of adiponectin on Ang II-induced RhoA activation was attenuated by L-NAME $(2 \mathrm{mmol} / \mathrm{L})$ and cGMPS (50 $\mathrm{nmol} / \mathrm{L})$, indicating the involvement of NO action in the inhibitory effect of adiponectin on Ang II-induced RhoA activation.

\section{NO Attenuates Ang II-Induced RhoA Activation}

The ability of NO to inhibit RhoA activity has been studied in cardiac cells (Kuwahara et al., 1999) and VSMC (Murthy et al., 2003). In this study, we examined whether the antihypertrophic effect of NO was mediated via inhibition of Ang II-induced RhoA activation after $10 \mathrm{~min}$ of Ang II treatment in endothelium-intact aortic rings. Figure 3A show that SNAP (NO donor; $0.1 \mathrm{mmol} / \mathrm{L}$ ) significantly inhibited Ang II-induced RhoA activation (Figure 3A).

In order to examine the translocation of RhoA after $30 \mathrm{~min}$ of Ang II treatment, we performed a Western blot analysis on cytosolic and membrane fractions of rat aortic rings. In addition, we examined whether the anti-hypertrophic
A

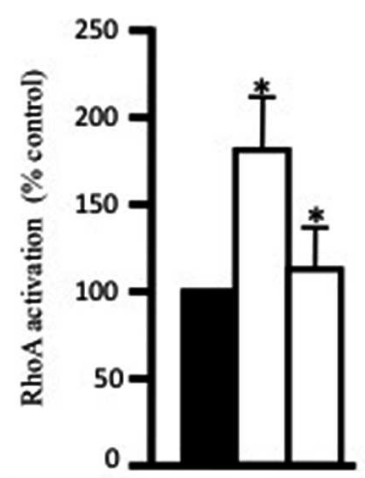

Ang II $(1 \mu \mathrm{mol})-++$

SNAP $(0.1 \mathrm{mmol})$ - - +
B

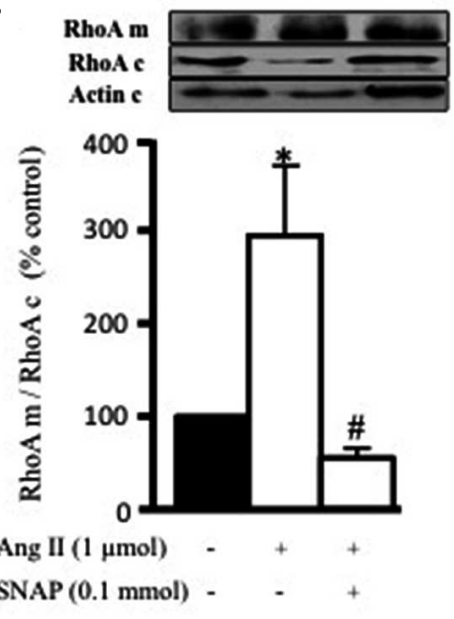

\section{C}

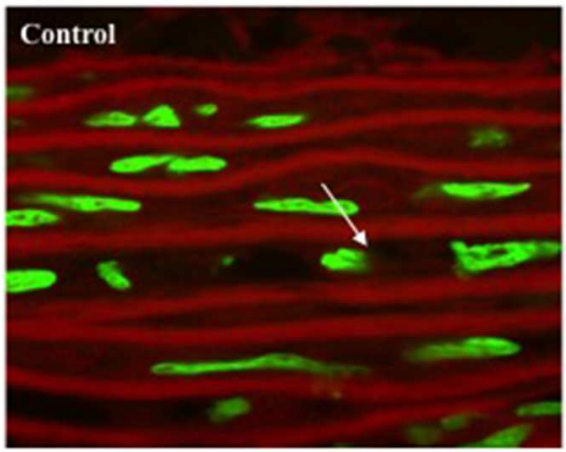

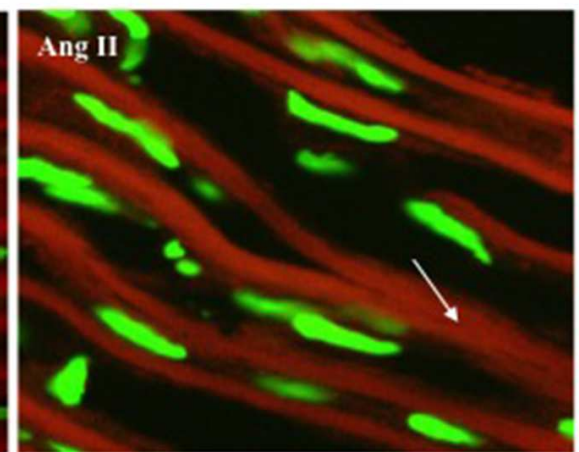

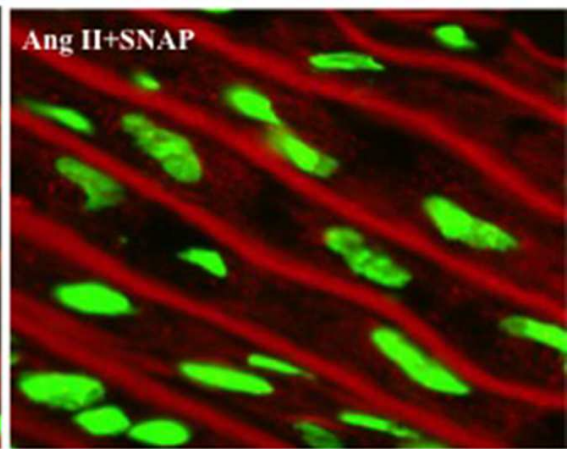

FIGURE 3 | Nitric oxide (NO) inhibits Ang II-induced RhoA activation and translocation. (A) Endothelium-intact rat aortic rings were cultured for 10 min with or without $1 \mu \mathrm{mol} / \mathrm{L}$ Ang II pre-treated with/without SNAP and RhoA activation was analyzed with G-LISA kit BK121. (B) A representative Western blot showing RhoA membrane fraction (RhoA m), RhoA cytosolic fraction (RhoA c) and actin (actin c) after 30 min treatment with Ang II in aortic rings. Ang II caused a threefold increase in membrane bound RhoA whereas SNAP inhibited RhoA translocation. Each bar represents mean \pm SEM value obtained from 3 to 7 independent experiments. ${ }^{*} p<0.05$ vs. without Ang II. \#p $<0.05$ vs. with Ang II. (C) Confocal images for aortic ring frozen sections stained with DAPI (green) and anti-RhoA antibody (red) treated with Ang II for 30 min with or without SNAP. Control (left panel), Ang II (middle panel), Ang II + SNAP (right panel). 
effect of $\mathrm{NO}$ was mediated via inhibition of Ang II-induced RhoA translocation, using SNAP. Treatment with Ang II significantly increased RhoA translocation from the cytosol to the cell membrane by almost threefold as compared to controls (Figures 3B,C). This was assessed as the ratio of total RhoA in the membrane to that in the cytosol. As expected, SNAP significantly inhibited Ang II-induced RhoA translocation (Figures 3B,C).

\section{NO Attenuates Ang II-Induced Cofilin-2 Phosphorylation}

To further confirm RhoA translocation and activation as a potential mediator of Ang II-induced hypertrophy in endothelium-intact aortic rings, we assessed the phosphorylation of cofilin-2, an actin depolymerizing protein and a downstream effector of RhoA/ROCK activation. Ang II (1 $\mu \mathrm{mol} / \mathrm{L})$ significantly increased cofilin-2 phosphorylation, as compared to control, in a time-dependent manner, with a peak at $15 \min \left({ }^{*} p<0.05\right.$, Figure 4A). This indicates that cofilin2 is phosphorylated and thus inhibited by Ang II-induced RhoA translocation, an indicator of RhoA/ROCK pathway activation. In order to investigate whether NO modulates Ang II-induced cofilin-2 phosphorylation, SNAP (0.1 $\mathrm{mmol} / \mathrm{L})$ was used as source of NO. Figure 4B shows that Ang II-induced cofilin-2 phosphorylation was significantly inhibited by $\mathrm{NO}$ in comparison to Ang II alone after $15 \mathrm{~min}$ $\left({ }^{*} p<0.05\right)$.

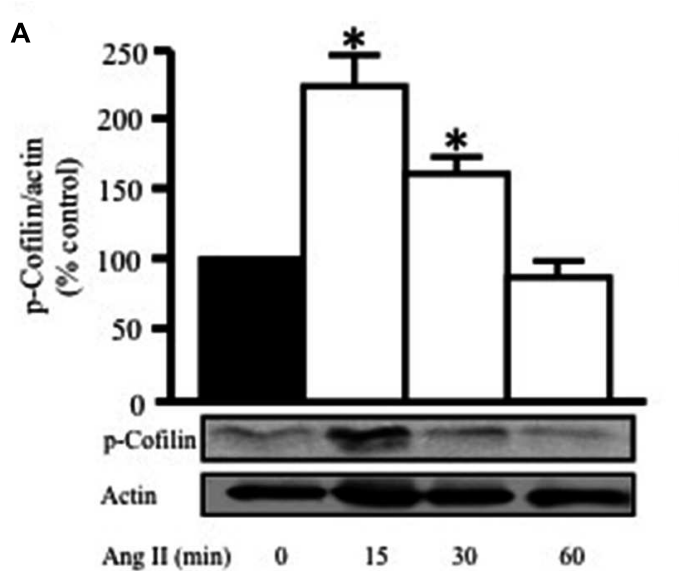

D

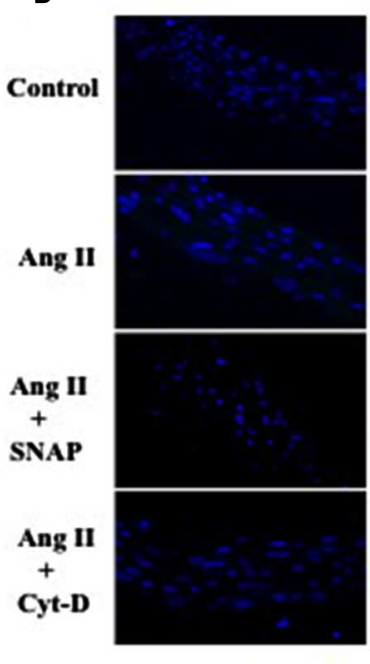

DAPI

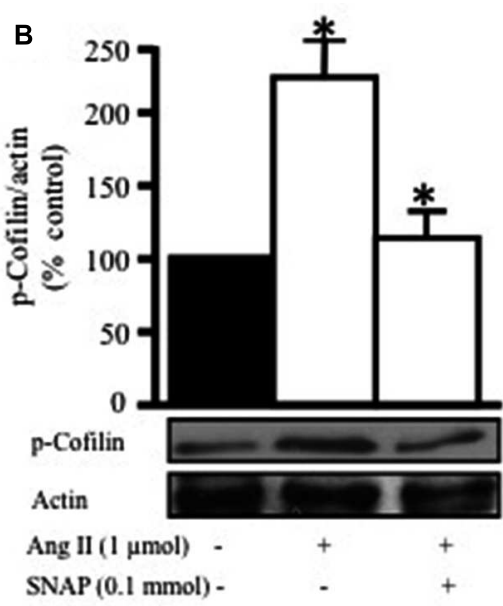

C

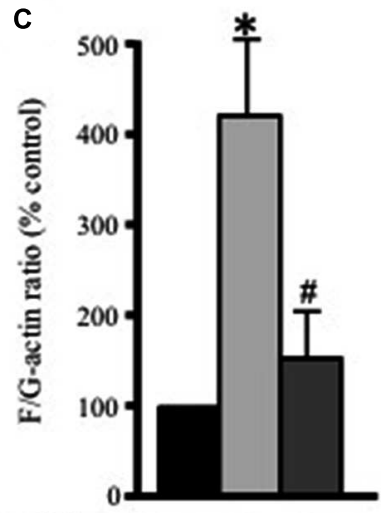

Ang II $(1 \mu \mathrm{mol})-++$ $\operatorname{SNAP}(0.1 \mathrm{mmol}) \cdot-+$

FIGURE 4 | Nitric oxide attenuates Ang II-induced RhoA/ROCK pathway activation and actin cytoskeleton remodeling. (A) Endothelium-intact rat aortic rings were treated for various times $(0,15,30$, and $60 \mathrm{~min})$ with $1 \mu \mathrm{mol} / \mathrm{L}$ Ang $\|$ and cofilin-2 phosphorylation was analyzed by Western Blotting. $n=5 ;{ }^{*} p<0.05$. (B) SNAP significantly inhibited Ang II-induced cofilin-2 phosphorylation after 15 min. Endothelium-intact rat aortic rings were treated with Ang II for 24 h with or without SNAP followed by quantification of F/G-actin ratio (C). Confocal images of aortic ring sections stained with DAPI (blue, nucleus), Deoxyribonuclease-I Alexa Fluor 488 (green, G-actin) and F-Phalloidin-555 actin stain (red, F-actin). Rat aortas were treated for $24 \mathrm{~h}$ with $1 \mu \mathrm{mol} / \mathrm{L}$ Ang II in the presence or absence of SNAP $(0.1 \mathrm{mmol} / \mathrm{L})$ or Cyt-D $(1 \mu \mathrm{mol} / \mathrm{L})$ and relative amounts of $\mathrm{F}$ - and $\mathrm{G}$-actin were assessed (D). $n=5-7$; * $p<0.05$ vs. without Ang II; \#p < 0.05 vs. with Ang II. 


\section{NO Modulates Ang II-Induced Actin Cytoskeleton Remodeling}

Previous studies demonstrated that actin cytoskeleton dynamics are the major target of phosphorylated cofilin-2 in the RhoA/ROCK pathway (Zeidan et al., 2006). In this study we investigated the effect of Ang II treatment for $24 \mathrm{~h}$ on variations of F- to G-actin ratio in endothelium-intact aortic rings. Ang II ( $1 \mu \mathrm{mol} / \mathrm{L}$ ) significantly increased F/G-actin ratio by fourfold, indicating a large pool of filamentous F-actin in comparison to $\mathrm{G}$-actin $\left({ }^{*} p<0.05\right.$, Figure $\left.4 \mathrm{C}\right)$. However, this effect was completely inhibited by SNAP treatment (Figure 4C). Thus, Ang II-activation of RhoA indeed induces changes in actin cytoskeleton dynamics, which is inhibited by NO.

To further confirm our findings, confocal microscopy was performed (Figure 4D) using Phalloidin and Deoxyribonuclease I to stain F-actin (red) and G-actin (green), respectively. The nuclei of VSMC were stained with DAPI for DNA (blue). Control aortic ring sections showed more G-actin compared to F-actin (Figure 4D). On the other hand, Ang II-treated aortic rings for
24 h showed a significant increase in F-actin compared to G-actin (Figure 4D). However, F-actin was markedly decreased following SNAP $(0.1 \mathrm{mmol} / \mathrm{L})$ or Cyt-D ( $1 \mu \mathrm{mol} / \mathrm{L}$; Ghantous et al., 2015b) treatment (Figure 4D). These results suggest that the protective effect of NO is mediated by actin cytoskeleton dynamics through increasing $\mathrm{F} / \mathrm{G}$-actin ratio.

\section{Adiponectin and NO Inhibit Ang II-Induced ROS Production}

Reactive oxygen species has been shown to be implicated in the development of vascular hypertrophy (Ghantous et al., 2015b). In order to determine whether Ang II-induced hypertrophy is associated with ROS production, endothelium-intact aortic rings were stained with $\mathrm{DHE}$ and viewed using a laser confocal microscope. Untreated aortic section barely generated ROS (Figure 5A). Ang II treatment for $1 \mathrm{~h}$ noticeably upregulated ROS formation in comparison to control aortas (Figure 5A). However, adiponectin and SNAP completely inhibited Ang II-induced ROS production (Figure 5A), as compared to Ang II-treated aortas.

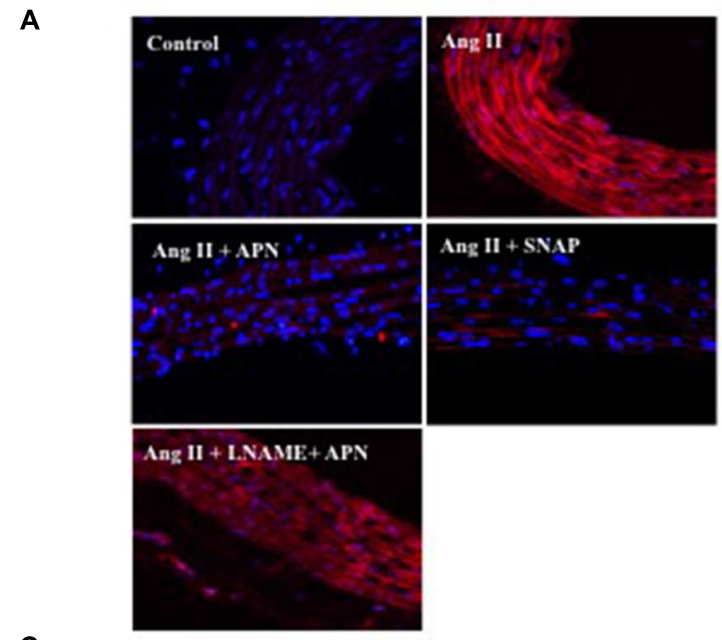

C

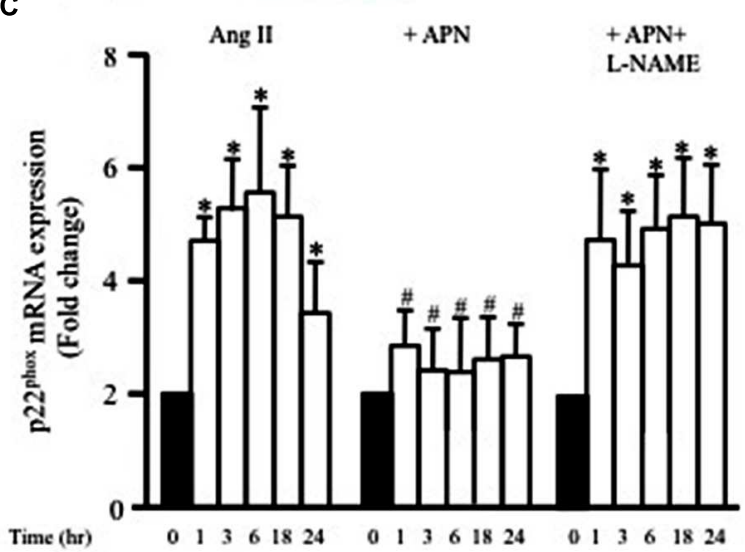

B

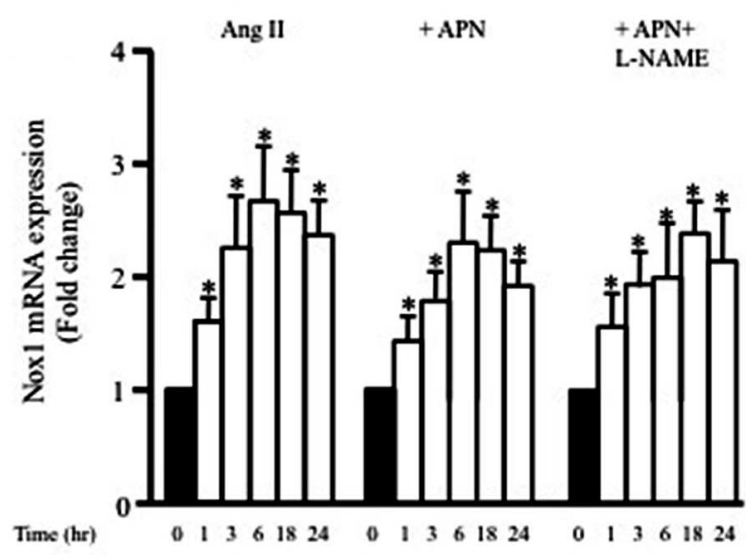

D

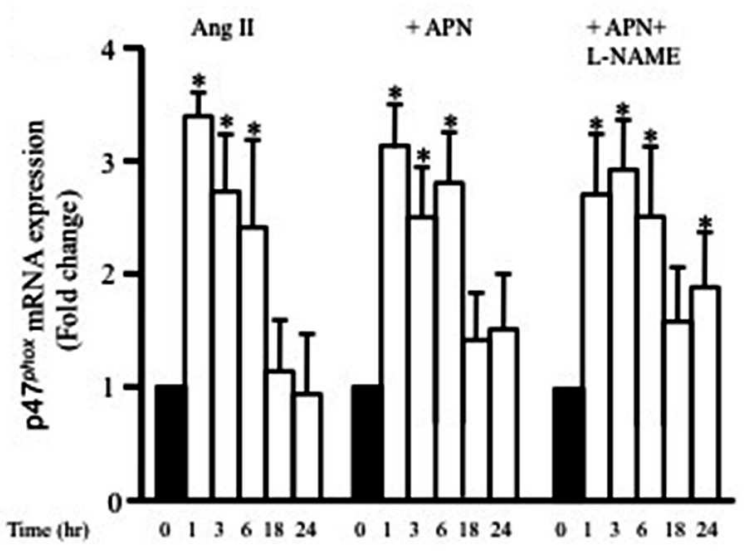

FIGURE 5 | Nitric oxide mediates the inhibitory effect of adiponectin on Ang II-induced ROS formation and p22 ${ }^{\text {phox }}$ mRNA overexpression. (A) Representative confocal microscopic images of aortic wall treated with Ang II for $1 \mathrm{~h}$, with or without inhibitors and agonists, followed by staining with DHE (red). DAPI stained the nuclei blue. Fold change of Nox1 (B), p22 ${ }^{\text {phox }}$ (C), and p47 ${ }^{\text {phox }}$ (D) mRNA expression levels in the aortic rings after 0, 1, 3, 6, 18, 24 h of Ang II $(1 \mu \mathrm{mol} / \mathrm{L})$ treatment. $n=8-10$ in each group; * $p<0.05$ vs. control, $\# p<0.05$ vs. with Ang II. 
The inhibitory effect of adiponectin on Ang II-induced ROS formation (for $1 \mathrm{~h}$ ) was abolished by L-NAME, indicating the involvement of $\mathrm{NO}$ action in the inhibitory effect of adiponectin on Ang II-induced ROS formation.

\section{Ang II-Induced p22 ${ }^{\text {phox }}$ mRNA Expression is Inhibited by NO and cGMP}

NADPH oxidase (Nox) expression and activity are critical factors for ROS formation in various cells types, including VSMC. To examine whether Ang II enhanced the expression of Nox1 mRNA, endothelium-intact aortic rings were stimulated with Ang II $(1 \mu \mathrm{mol} / \mathrm{L})$ for $1,3,6,18$, or $24 \mathrm{~h}$ and the mRNA expressions of Nox1 was analyzed using qPCR. Figure 5B shows that Ang II significantly enhanced Nox1 expression after $1 \mathrm{~h}$ and was further enhanced up to $24 \mathrm{~h}$. We also assessed whether adiponectin $(5 \mu \mathrm{g} / \mathrm{ml})$ could prevent the Ang II-induced upregulation of Nox1 mRNA expression using qPCR analysis. Figure 5B shows that adiponectin and adiponectin + L-NAME had no effect on Ang II-induced Nox1 overexpression.

To explore further the involvement $\mathrm{p} 47^{\text {phox }}$ and $\mathrm{p} 22^{\mathrm{phox}}$ on Ang II-induced ROS formation in VSMC, we investigated whether the expression of $\mathrm{p} 47^{\text {phox }}$ and $\mathrm{p} 22^{\text {phox }} \mathrm{mRNA}$ in endothelium-intact aortic rings could be modified by Ang II treatment. Ang II significantly increased both $\mathrm{p} 47^{\text {phox }}$ and $\mathrm{p} 22^{\text {phox }}$ mRNA expression in a time-dependent manner (Figures 5C,D). Upregulation of $\mathrm{p} 47^{\text {phox }}$ mRNA expression induced by Ang II was not affected when aortic rings were pre-treated with adiponectin compared with the controls (Figure 5D). On the other hand, adiponectin significantly decreased $\mathrm{p} 22^{\text {phox }}$ mRNA expression compared with the Ang II-treated group (Figure 5C). Collectively, these data indicate the inhibitory effect of adiponectin on Ang II-induced p22 phox overexpression but not on Ang II-induced Nox1 or $\mathrm{p} 47^{\text {phox }}$ overexpression.

To determine whether adiponectin inhibits Ang II-induced p22 $2^{\text {phox }}$ overexpression through NO synthesis, L-NAME was used. Figure 5C shows L-NAME significantly attenuates the inhibitory effect of adiponectin on Ang II-induced p22 phox overexpression in endothelium-intact aortic rings. Next, we determined whether increased Nox1, p47 $7^{\text {phox }}$, or p22 $2^{\text {phox }}$ mRNA expression by Ang II was inhibited by SNAP or cGMP. Neither NO or cGMP had any effect on Ang II-induced Nox1 or $\mathrm{p} 47^{\text {phox }}$ expression (Figures 6A,C). Similar to adiponectin effect, $\mathrm{NO}$ and cGMP significantly inhibited Ang II-induced p22 phox overexpression (Figure 6B).

\section{A}

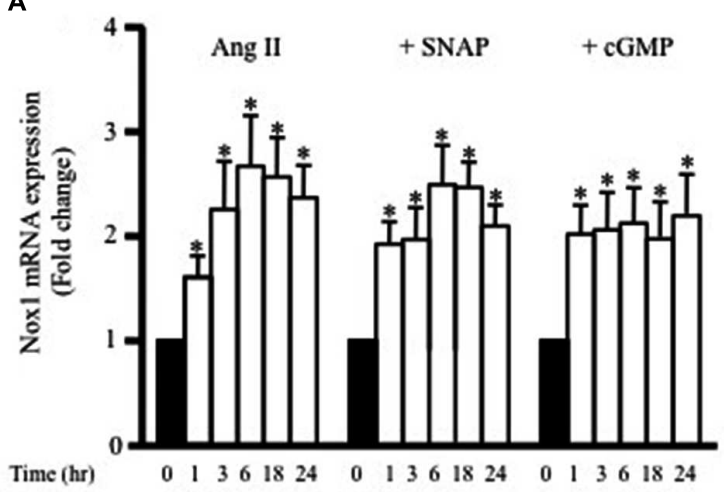

B

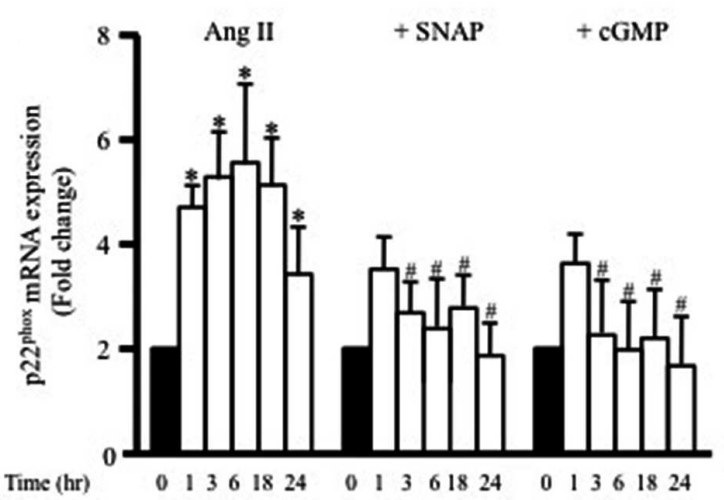

C

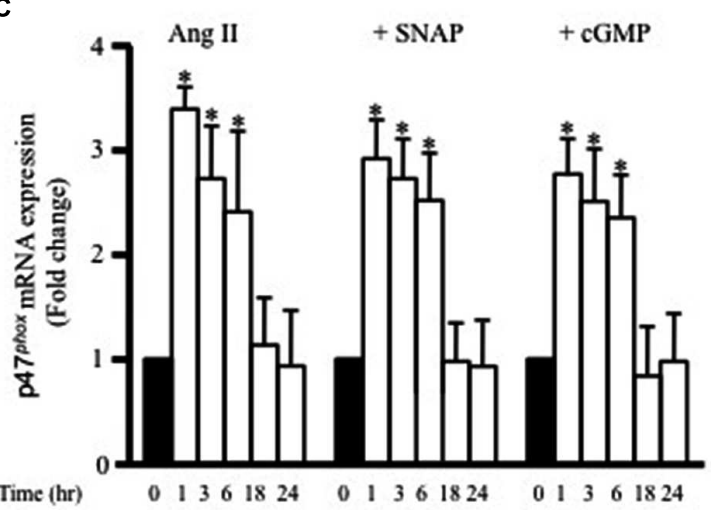

FIGURE 6 | S-nitroso- $\mathbf{N}$-acetylpenicillamine and cGMP attenuate Ang II-induced p22 ${ }^{\text {phox }}$ mRNA expression. Fold change of Nox1 (A), p22 ${ }^{\text {phox }}$ (B), and $\mathrm{p} 47^{\text {phox }}$ (C) $m R N A$ expression levels in the endothelium-intact rat aortic rings after $0,1,3,6,18,24 \mathrm{~h}$ of Ang II (1 $\mu$ mol/L) treatment. $n=8-10$ in each group; $* p<0.05$ vs. control; $\# p<0.05$ vs. with Ang II. 


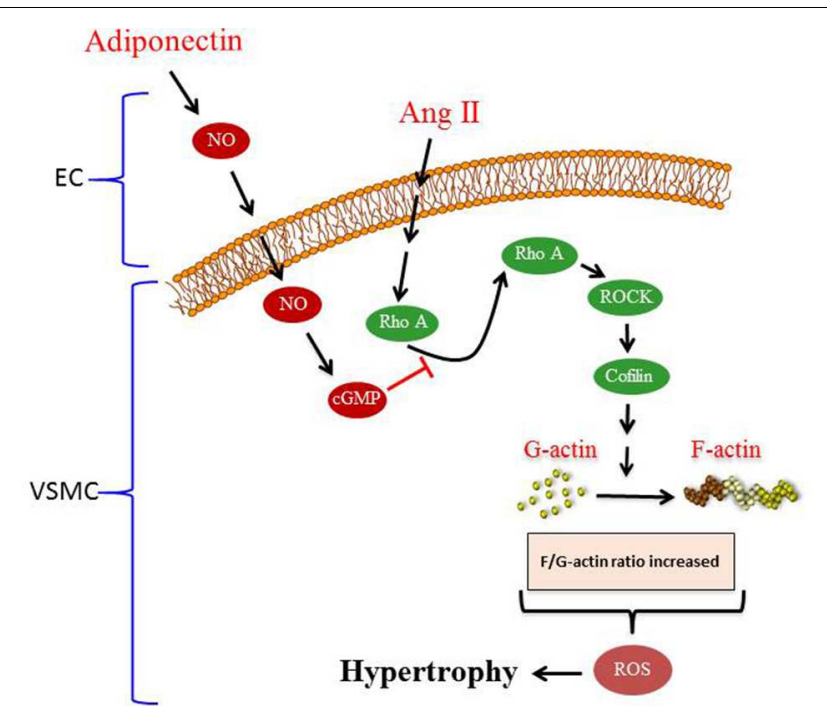

FIGURE 7 | Proposed model of adiponectin-mediated inhibition of Ang II-induced VSMC remodeling. Treatment with Ang II induces hypertrophy in VSMC. Adiponectin suppresses Angll-induced VSMC hypertrophy through signaling pathways that activates NO synthesis in endothelial cells (ECs). The inhibitory effect of adiponectin on Ang II-induced VSMC hypertrophy is mediated through modulating the RhoA/ROCK signaling pathway, F-actin to G-actin ratio, and ROS formation.

\section{DISCUSSION}

Hypertension is a key risk factor for cardiovascular disease. Abnormal vascular structure and function, such as hypertrophy, increased constrictor, or decreased dilatory responses, are major aspects underlying vascular pathology in hypertension (Touyz, 2003). Ang II, an endogenous vasoconstrictor, contributes to these aspects mainly by inducing vascular hypertrophy (Zhang et al., 2005; Li et al., 2011). The ability of Ang II to activate both ROS production and RhoA/ROCK pathway has been previously investigated, suggesting the emergence of these pathways as critical components of the hypertrophy program (Zeidan et al., 2005; Jin et al., 2006) and as such represent possible targets for therapeutic intervention. The purpose of our study was to investigate whether the anti-hypertrophic effect of adiponectin on Ang II-induced hypertrophy is mediated by NO synthesis and due to inhibition of RhoA activation and ROS formation.

To our knowledge, the major novel findings in our study are (1) adiponectin attenuates Ang II-induced VSMC hypertrophy, (2) adiponectin displays anti-oxidant effects and suppresses the expression of $\mathrm{p} 22^{\text {phox }}$ mRNA expression, but not Nox1 and p4 $7^{\text {phox }}$ mRNA expression in Ang II-stimulated aortic rings, and (3) the anti-hypertrophic and anti-oxidant effects of adiponectin are mediated by NO synthesis and action (Figure 7).

Recent studies portrayed adiponectin as a cardioprotective hormone in obesity-related diseases, such as hypertrophic cardiomyopathy, and its ability to maintain the cardiovascular function (Ouchi et al., 2006; Kitaoka et al., 2010). Indeed, in contrast to other adipokines, circulating APN levels are reduced in cardiovascular diseases (Shetty et al., 2009). The effects of APN occur through interaction with specific APN receptors, AdipoR1 and AdipoR2. These receptors are expressed in several cells including VSMC (reviewed by Ghantous et al., 2015a). Upon binding to its receptors, adiponectin activates several signal transduction pathways mediated by AMPK and PPAR $\alpha$ (Yamauchi and Kadowaki, 2013). Through activation of AMP-activated protein kinase signaling, adiponectin has been demonstrated to inhibit the hypertrophic effect of Ang II on cardiac tissue (Wang et al., 2010). Adiponectin-deficient mice exposed to pressure overload showed increased cardiac hypertrophy, while supplementation of adiponectin protected against the development of cardiac hypertrophy in response to angiotensin II (Shibata et al., 2004). To our knowledge, there aren't studies done on angiotensin II-infusion in adiponectin receptor-deficient mice. However, angiotensin II-infusion done on normal rats induced cardiac hypertrophy and reduced the expression of AdipoR1 but not AdipoR2 (Li et al., 2013). Angiotensin II-infusion also reduced circulating levels of adiponectin (Li et al., 2013).

To date and to our knowledge, there are no studies that have examined the anti-hypertrophic effect of adiponectin in Ang II-induced vascular hypertrophy. In this study, we approached this question and we showed the anti-hypertrophic effect of adiponectin on Ang II-induced vascular hypertrophy. The next step was to understand the molecular mechanism of the antihypertrophic effect of adiponectin. Increasing attention has recently been focused on the role of ROS in adiponectin signal transduction (Fujimoto et al., 2010; Yuan et al., 2012). Accumulating evidence suggests that ROS is involved in the hypertrophic responses to Ang II (Schiffrin and Touyz, 2003; Dai et al., 2011). ROS mediates VSMC hypertrophy through activation of different signaling pathways such as ERK1/2, different transcription factors, and ion channels. NADPH oxidase (Nox) generates superoxides that affect different cellular functions (Hingtgen et al., 2006). Nox1, an isoform of Nox family, exists in VSMC and participates in many vascular functions, such as muscle contraction (Matsuno et al., 2005). Nox1 is composed of several subunits including $\mathrm{p} 22^{\text {phox }}$ and $\mathrm{p} 47^{\text {phox }}$. Both $\mathrm{p} 22^{\text {phox }}$ and $\mathrm{p} 47^{\text {phox }}$ are necessary for Nox1 function and stability (Lambeth, 2004), which leads to ROS formation. Additionally, several studies have shown that Ang II induces ROS formation through upregulation of different NADPH oxidase subunits, including Nox $1, \mathrm{p} 47^{\text {phox }}$, and $\mathrm{p} 22^{\text {phox }}$ in cardiac and vascular cells (Touyz et al., 2005; Thomas et al., 2006). Our results in this study show, in the first place, that adiponectin has the ability to inhibit Ang II-induced ROS formation and p22 phox mRNA expression. Interestingly, treatment with adiponectin failed to inhibit the expression of both Nox 1 and $\mathrm{p} 47^{\mathrm{phox}}$. As far as we know, this is the first report of the protective effect of adiponectin on ROS and downregulation of $\mathrm{p} 22^{\text {phox }} \mathrm{mRNA}$ expression.

To evaluate the molecular mechanisms underlying the inhibitory effect of adiponectin on ROS formation and $\mathrm{p} 22^{\text {phox }}$ mRNA expression in Ang II-stimulated aortic rings, we investigated the influence of the NO synthesis inhibitor LNAME on adiponectin's anti-oxidant effect. NO has many cardioprotective actions on the cardiovascular system during hypertension (Tanaka and Node, 2015). The major functions of 
NO on the cardiovascular system include anti-inflammatory, anti-proliferative, anti-thrombotic, and anti-hypertrophic activity (Tziros and Freedman, 2006; Garcia and Incerpi, 2008; Momi et al., 2012). However, the exact molecular mechanisms of the anti-hypertrophic effect of NO on Ang II-induced VSMC hypertrophy remain unclear. VSMC contractility is associated with hypertrophy when exposed to high stress such as hypertension. We and others have shown that Ang II significantly increased the VSMC force-generating ability in response to high$\mathrm{K}^{+}$depolarization (Garcha et al., 2001). Different studies have shown the involvement of the RhoA/ROCK pathway, which is activated by Ang II (Yamakawa et al., 2000), in VSMC contraction (Sakamoto et al., 2003; Zeidan et al., 2003). The observed increase in force generation was associated with increased fiber stress formation (increased F-actin to G-actin ratio). Indeed, actin cytoskeleton remodeling and stress formation are a welldescribed consequence of RhoA/ROCK pathway activation (Zeidan et al., 2007). It is reasonable to speculate that actin cytoskeleton modulation would increase the contractile potential of VSMC. Another potential factor that leads to increased force production is myosin light chain phosphatase (MLCP). Inhibition of MLCP by RhoA/ROCK pathway has been shown to increase calcium sensitivity, leading to an increase in muscle contraction (Mizuno et al., 2008).

In this study we have investigated the role of Rho A activation and translocation in Ang II -induced VSMC remodeling. To activate the RhoA/ROCK pathway, RhoA must first be activated by binding to GTP [by guanine nucleotide exchange factors (GEFs)], then translocated to the cell membrane, followed by subsequent activation of ROCK and the pathway (Zeidan et al., 2007). We have shown that Ang II treatment caused a significant activation in RhoA after 5 min, which peaked after 10 min (Figure 2A). We then examined whether RhoA activation was followed by its translocation to the membrane. Ang II treatment for 15 min showed some RhoA translocation to the membrane, while $30 \mathrm{~min}$ of Ang II treatment induced a marked increase in RhoA translocation (Figure 2B). Hence, RhoA activation after $10 \mathrm{~min}$ of Ang II treatment was indeed followed by its translocation to the membrane, which began after $15 \mathrm{~min}$ and peaked after $30 \mathrm{~min}$ of Ang II treatment. Since changes in F-actin and G-actin cytoskeleton dynamics are the downstream targets of RhoA/ROCK pathway, their levels were examined. Indeed, time-course experiments for F- and G-actin cytoskeleton dynamics (unpublished data) showed that the changes are most prominent after $24 \mathrm{~h}$, in both VSMC and cardiomyocytes (Zeidan et al., 2006, 2007, 2008; Ghantous et al., 2015b).

Nitric oxide is a gaseous molecule that acts as a vasodilating factor in VSMC while it's an anti-hypertrophic factor in both VSMC and cardiomyocytes (Hunter et al., 2009; Van Hove et al., 2009). It diffuses easily to VSMC, across the plasma membrane, and causes their relaxation by reducing intracellular calcium levels (Van Hove et al., 2009). NO attenuates VSMC contraction and hypertrophy by inhibiting ROCK in the RhoA/ROCK pathway (Maruhashi et al., 2014). The antihypertrophic effect of NO is associated with vasodilatory actions though cGMP formation and phosphorylation of PKG (Kapakos et al., 2010). Our data show that culturing endothelium-intact aortic rings either with $\mathrm{NO}$ or adiponectin in presence of Ang II for $24 \mathrm{~h}$ significantly decreased force production of aorta in response to high- $\mathrm{K}^{+}$depolarization compared to tissues cultured with Ang II alone. Inhibition of NO synthesis by L-NAME or cGMP-dependent protein kinase by Rp-8-r-PETcGMPS (cGMPS) ameliorated adiponectin's effect on Ang IIinduced force production and ROS formation, indicating the necessity of NO/cGMP pathway for the inhibitory effect of adiponectin against Ang II-induced increased in muscle force production, and ROS formation. This data provide insight into how this circulating adipokine might attenuate Ang IIinduced vasoconstriction and ROS formation through NO production.

To further explore another possible mechanism of the antihypertrophic effect of adiponectin, we attempted to investigate the involvement of the RhoA/ROCK pathway. Indeed, numerous studies have implicated the potential involvement of RhoA activation and increased stress fiber formation with the hypertrophic effect of Ang II (Yamakawa et al., 2000; Jin et al., 2006). Upon stimulation, RhoA activates a signaling cascade involving ROCK, LIMK, and cofilin-2, an actin depolymerizing enzyme that binds to actin and prevents stress fiber formation (Zeidan et al., 2007). As such, when cofilin-2 is phosphorylated (inactivated) by LIMK, the F/G-actin equilibrium is shifted toward enhanced stress fiber formation or more F-actin formation (Zeidan et al., 2008). Consistent with the previously reported findings (Hunter et al., 2009; Zeidan et al., 2014), our results also demonstrate that Ang II-induced RhoA activation and translocation are associated with cofilin-2 phosphorylation and enhanced stress fiber formation, which were abolished by treatment with NO synthesis. The effect of Ang II on cofilin-2 phosphorylation and actin cytoskeleton remodeling was abolished in aortic tissue treated with NO donor, indicating that the anti-hypertrophic effect of NO may be mediated via inhibition of RhoA activation and its downstream signaling. In addition, we showed that the ability of adiponectin to modulate the effect of Ang II on RhoA activation and actin cytoskeleton dynamics was mediated through NO synthesis.

Overall, our study provides insight into the signal transduction pathway mediating the anti-hypertrophic properties of adiponectin during hypertension. The proposed mechanism underlying the anti-hypertrophic effect of adiponectin on Ang II-induced hypertrophy is shown in Figure 7. Our study highlights the effects of adiponectin on cellular NO synthesis, ROS generation, RhoA/ROCK pathway, and actin cytoskeleton dynamics. Our findings could be useful in the development of novel adiponectin-targeted therapeutic interventions for the treatment of vascular hypertrophy during hypertension.

\section{AUTHOR CONTRIBUTIONS}

WN-E, CMG, LD, HI, and AZ contributed in generating experimental data. CMG, NE-Z, Hana A. Itani, KZ, and $\mathrm{AZ}$ contributed in discussion and reviewed/edited manuscript. $\mathrm{CMG}, \mathrm{KZ}$, and $\mathrm{AZ}$ wrote the manuscript and drew the figures. 


\section{FUNDING}

This work was supported by Medical Practice Plan (MPP), Faculty of Medicine at AUB to AZ.

\section{REFERENCES}

Bagi, Z., Feher, A., Cassuto, J., Akula, K., Labinskyy, N., Kaley, G., et al. (2011). Increased availability of angiotensin AT 1 receptors leads to sustained arterial constriction to angiotensin II in diabetes - role for Rho-kinase activation. Br. J. Pharmacol. 163, 1059-1068. doi: 10.1111/j.1476-5381.2011.01307.x

Carbone, M. L., Bregeon, J., Devos, N., Chadeuf, G., Blanchard, A., Azizi, M., et al. (2015). Angiotensin II activates the RhoA exchange factor Arhgef1 in humans. Hypertension 65, 1273-1278. doi: 10.1161/HYPERTENSIONAHA.114.05065

Caselli, C., D’amico, A., Cabiati, M., Prescimone, T., Del Ry, S., and Giannessi, D. (2014). Back to the heart: the protective role of adiponectin. Pharmacol. Res. 82, 9-20. doi: 10.1016/j.phrs.2014.03.003

Coles, B., Fielding, C. A., Rose-John, S., Scheller, J., Jones, S. A., and O'donnell, V. B. (2007). Classic interleukin-6 receptor signaling and interleukin- 6 trans-signaling differentially control angiotensin II-dependent hypertension, cardiac signal transducer and activator of transcription-3 activation, and vascular hypertrophy in vivo. Am. J. Pathol. 171, 315-325. doi: 10.2353/ajpath.2007.061078

Dai, D. F., Johnson, S. C., Villarin, J. J., Chin, M. T., Nieves-Cintron, M., Chen, T., et al. (2011). Mitochondrial oxidative stress mediates angiotensin II-induced cardiac hypertrophy and Galphaq overexpression-induced heart failure. Circ. Res. 108, 837-846. doi: 10.1161/CIRCRESAHA.110.232306

Day, B. J., Patel, M., Calavetta, L., Chang, L. Y., and Stamler, J. S. (1999). A mechanism of paraquat toxicity involving nitric oxide synthase. Proc. Natl. Acad. Sci. U.S.A. 96, 12760-12765. doi: 10.1073/pnas.96.22.12760

Fujimoto, A., Akifusa, S., Kamio, N., Hirofuji, T., Nonaka, K., and Yamashita, Y. (2010). Involvement of mTOR in globular adiponectininduced generation of reactive oxygen species. Free Radic. Res. 44, 128-134. doi: 10.3109/10715760903348328

Fujita, K., Maeda, N., Sonoda, M., Ohashi, K., Hibuse, T., Nishizawa, H., et al. (2008). Adiponectin protects against angiotensin II-induced cardiac fibrosis through activation of PPAR-alpha. Arterioscler. Thromb. Vasc. Biol. 28, 863-870. doi: 10.1161/ATVBAHA.107.156687

Furchgott, R. F. (1983). Role of endothelium in responses of vascular smooth muscle. Circ. Res. 53, 557-573. doi: 10.1161/01.RES.53.5.557

Garcha, R. S., Sever, P. S., and Hughes, A. D. (2001). Mechanism of action of angiotensin II in human isolated subcutaneous resistance arteries. $\mathrm{Br}$. J. Pharmacol. 134, 188-196. doi: 10.1038/sj.bjp.0704222

Garcia, J. A., and Incerpi, E. K. (2008). Factors and mechanisms involved in left ventricular hypertrophy and the anti-hypertrophic role of nitric oxide. Arq. Bras. Cardiol. 90, 409-416.

Ghantous, C. M., Azrak, Z., Hanache, S., Abou-Kheir, W., and Zeidan, A. (2015a). Differential role of leptin and adiponectin in cardiovascular system. Int. J. Endocrinol. 2015, 534320. doi: 10.1155/2015/534320

Ghantous, C. M., Kobeissy, F. H., Soudani, N., Rahman, F. A., Al-Hariri, M., Itani, H. A., et al. (2015b). Mechanical stretch-induced vascular hypertrophy occurs through modulation of leptin synthesis-mediated ROS formation and GATA-4 nuclear translocation. Front. Pharmacol. 6:240. doi: 10.3389/fphar.2015.00240

Heeneman, S., Sluimer, J. C., and Daemen, M. J. (2007). Angiotensinconverting enzyme and vascular remodeling. Circ. Res. 101, 441-454. doi: 10.1161/CIRCRESAHA.107.148338

Hingtgen, S. D., Tian, X., Yang, J., Dunlay, S. M., Peek, A. S., Wu, Y., et al. (2006). Nox2-containing NADPH oxidase and Akt activation play a key role in angiotensin II-induced cardiomyocyte hypertrophy. Physiol. Genomics 26, 180-191. doi: 10.1152/physiolgenomics.00029.2005

Hofbauer, K. H., Schoof, E., Kurtz, A., and Sandner, P. (2002). Inflammatory cytokines stimulate adrenomedullin expression through nitric oxidedependent and -independent pathways. Hypertension 39, 161-167. doi: 10.1161/hy1201.097201

Homma, N., Nagaoka, T., Morio, Y., Ota, H., Gebb, S. A., Karoor, V., et al. (2007). Endothelin-1 and serotonin are involved in activation of RhoA/Rho kinase

\section{ACKNOWLEDGMENT}

We would like to thank all members of the Zeidan's Laboratory for their support, especially Mrs. Nadia Soudani.

signaling in the chronically hypoxic hypertensive rat pulmonary circulation. J. Cardiovasc. Pharmacol. 50, 697-702. doi: 10.1097/FJC.0b013e3181593774

Hunter, J. C., Zeidan, A., Javadov, S., Kilic, A., Rajapurohitam, V., and Karmazyn, M. (2009). Nitric oxide inhibits endothelin-1-induced neonatal cardiomyocyte hypertrophy via a RhoA-ROCK-dependent pathway. J. Mol. Cell. Cardiol. 47, 810-818. doi: 10.1016/j.yjmcc.2009.09.012

Jin, L., Ying, Z., Hilgers, R. H., Yin, J., Zhao, X., Imig, J. D., et al. (2006). Increased RhoA/Rho-kinase signaling mediates spontaneous tone in aorta from angiotensin II-induced hypertensive rats. J. Pharmacol. Exp. Ther. 318, 288-295. doi: 10.1124/jpet.105.100735

Jones, S. P., and Bolli, R. (2006). The ubiquitous role of nitric oxide in cardioprotection. J. Mol. Cell. Cardiol. 40, 16-23. doi: 10.1016/j.yjmcc.2005.09.011

Kapakos, G., Bouallegue, A., Daou, G. B., and Srivastava, A. K. (2010). Modulatory role of nitric oxide/cGMP system in endothelin-1-induced signaling responses in vascular smooth muscle cells. Curr. Cardiol. Rev. 6, 247-254. doi: $10.2174 / 157340310793566055$

Kawai, T., Ohishi, M., Takeya, Y., Onishi, M., Ito, N., Yamamoto, K., et al. (2013). Adiponectin single nucleotide polymorphism is a genetic risk factor for stroke through high pulse wave pressure: a cohort study. J. Atheroscler. Thromb. 20, 152-160. doi: 10.5551/jat.14696

Kim, D. H., Kim, C., Ding, E. L., Townsend, M. K., and Lipsitz, L. A. (2013). Adiponectin levels and the risk of hypertension: a systematic review and meta-analysis. Hypertension 62, 27-32. doi: 10.1161/HYPERTENSIONAHA.113.01453

Kitaoka, H., Kubo, T., Okawa, M., Yamasaki, N., Matsumura, Y., Nishinaga, M., et al. (2010). Plasma adiponectin levels and left ventricular remodeling in hypertrophic cardiomyopathy. Int. Heart J. 51, 51-55. doi: 10.1536/ihj.51.51

Kuwahara, K., Saito, Y., Nakagawa, O., Kishimoto, I., Harada, M., Ogawa, E., et al. (1999). The effects of the selective ROCK inhibitor, Y27632, on ET-1-induced hypertrophic response in neonatal rat cardiac myocytes-possible involvement of Rho/ROCK pathway in cardiac muscle cell hypertrophy. FEBS Lett. 452, 314-318. doi: 10.1016/S0014-5793(99)00680-8

Lambeth, J. D. (2004). NOX enzymes and the biology of reactive oxygen. Nat. Rev. Immunol. 4, 181-189. doi: 10.1038/nri1312

Lavigne, M. C., Malech, H. L., Holland, S. M., and Leto, T. L. (2001). Genetic demonstration of $\mathrm{p} 47$ phox-dependent superoxide anion production in murine vascular smooth muscle cells. Circulation 104, 79-84. doi: 10.1161/01.CIR.104.1.79

Li, L., Gao, P., Zhang, H., Chen, H., Zheng, W., Lv, X., et al. (2011). SIRT1 inhibits angiotensin II-induced vascular smooth muscle cell hypertrophy. Acta Biochim. Biophys. Sin. (Shanghai) 43, 103-109. doi: 10.1093/abbs/gmq104

Li, L., Zhang, Z. G., Lei, H., Wang, C., Wu, L. P., Wang, J. Y., et al. (2013). Angiotensin II reduces cardiac AdipoR1 expression through AT1 receptor/ROS/ERK1/2/c-Myc pathway. PLoS ONE 8:e49915. doi: 10.1371/journal.pone.0049915

Lin, L. Y., Lin, C. Y., Su, T. C., and Liau, C. S. (2004). Angiotensin II-induced apoptosis in human endothelial cells is inhibited by adiponectin through restoration of the association between endothelial nitric oxide synthase and heat shock protein 90. FEBS Lett. 574, 106-110. doi: 10.1016/j.febslet.2004. 08.012

Maruhashi, T., Noma, K., Iwamoto, Y., Iwamoto, A., Oda, N., Kajikawa, M., et al. (2014). Critical role of exogenous nitric oxide in ROCK activity in vascular smooth muscle cells. PLoS ONE 9:e109017. doi: 10.1371/journal.pone. 0109017

Matsuno, K., Yamada, H., Iwata, K., Jin, D., Katsuyama, M., Matsuki, M., et al. (2005). Nox1 is involved in angiotensin II-mediated hypertension: a study in Nox1-deficient mice. Circulation 112, 2677-2685. doi: 10.1161/CIRCULATIONAHA.105.573709

Mayer, B., Pfeiffer, S., Schrammel, A., Koesling, D., Schmidt, K., and Brunner, F. (1998). A new pathway of nitric oxide/cyclic GMP signaling involving 
S-nitrosoglutathione. J. Biol. Chem. 273, 3264-3270. doi: 10.1074/jbc.273. 6.3264

Menzaghi, C., Trischitta, V., and Doria, A. (2007). Genetic influences of adiponectin on insulin resistance, type 2 diabetes, and cardiovascular disease. Diabetes Metab. Res. Rev. 56, 1198-1209.

Mizuno, Y., Isotani, E., Huang, J., Ding, H., Stull, J. T., and Kamm, K. E. (2008). Myosin light chain kinase activation and calcium sensitization in smooth muscle in vivo. Am. J. Physiol. Cell Physiol. 295, C358-C364. doi: 10.1152/ajpcell.90645.2007

Molkentin, J. D., and Dorn, G. W. II (2001). Cytoplasmic signaling pathways that regulate cardiac hypertrophy. Annu. Rev. Physiol. 63, 391-426. doi: 10.1146/annurev.physiol.63.1.391

Momi, S., Monopoli, A., Alberti, P. F., Falcinelli, E., Corazzi, T., Conti, V., et al. (2012). Nitric oxide enhances the anti-inflammatory and anti-atherogenic activity of atorvastatin in a mouse model of accelerated atherosclerosis. Cardiovasc. Res. 94, 428-438. doi: 10.1093/cvr/cvs100

Montezano, A. C., and Touyz, R. M. (2012). Molecular mechanisms of hypertension-reactive oxygen species and antioxidants: a basic science update for the clinician. Can. J. Cardiol. 28, 288-295. doi: 10.1016/j.cjca.2012.01.017

Murthy, K. S., Zhou, H., Grider, J. R., and Makhlouf, G. M. (2003). Inhibition of sustained smooth muscle contraction by PKA and PKG preferentially mediated by phosphorylation of RhoA. Am. J. Physiol. Gastrointest. Liver Physiol. 284, G1006-G1016. doi: 10.1152/ajpgi.00465.2002

Ohashi, K., Kihara, S., Ouchi, N., Kumada, M., Fujita, K., Hiuge, A., et al. (2006). Adiponectin replenishment ameliorates obesity-related hypertension. Hypertension 47, 1108-1116. doi: 10.1161/01.HYP.0000222368.43759.a1

Ohashi, K., Ouchi, N., and Matsuzawa, Y. (2011). Adiponectin and hypertension. Am. J. Hypertens. 24, 263-269. doi: 10.1038/ajh.2010.216

Ouchi, N., Kihara, S., Arita, Y., Maeda, K., Kuriyama, H., Okamoto, Y., et al. (1999). Novel modulator for endothelial adhesion molecules: adipocytederived plasma protein adiponectin. Circulation 100, 2473-2476. doi: 10.1161/01.CIR.100.25.2473

Ouchi, N., Shibata, R., and Walsh, K. (2006). Targeting adiponectin for cardioprotection. Expert Opin. Ther. Targets 10, 573-581. doi: 10.1517/14728222.10.4.573

Pedrinelli, R., Ballo, P., Fiorentini, C., Denti, S., Galderisi, M., Ganau, A., et al. (2012). Hypertension and acute myocardial infarction: an overview. J. Cardiovasc. Med. (Hagerstown) 13, 194-202. doi: 10.2459/JCM.0b013e3283511ee2

Sakamoto, K., Hori, M., Izumi, M., Oka, T., Kohama, K., Ozaki, H., et al. (2003). Inhibition of high K+-induced contraction by the ROCKs inhibitor $\mathrm{Y}$ 27632 in vascular smooth muscle: possible involvement of ROCKs in a signal transduction pathway. J. Pharmacol. Sci. 92, 56-69. doi: 10.1254/jphs.92.56

Schiffrin, E. L., and Touyz, R. M. (2003). Inflammation and vascular hypertrophy induced by angiotensin II: role of NADPH oxidase-derived reactive oxygen species independently of blood pressure elevation? Arterioscler. Thromb. Vasc. Biol. 23, 707-709. doi: 10.1161/01.ATV.0000069907.12357.7E

Shetty, S., Kusminski, C. M., and Scherer, P. E. (2009). Adiponectin in health and disease: evaluation of adiponectin-targeted drug development strategies. Trends Pharmacol. Sci. 30, 234-239. doi: 10.1016/j.tips.2009.02.004

Shibata, R., Ouchi, N., Ito, M., Kihara, S., Shiojima, I., Pimentel, D. R., et al. (2004). Adiponectin-mediated modulation of hypertrophic signals in the heart. Nat. Med. 10, 1384-1389. doi: 10.1038/nm1137

Shibata, R., Sato, K., Pimentel, D. R., Takemura, Y., Kihara, S., Ohashi, K., et al. (2005). Adiponectin protects against myocardial ischemia-reperfusion injury through AMPK- and COX-2-dependent mechanisms. Nat. Med. 11, 1096-1103. doi: $10.1038 / \mathrm{nm} 1295$

Tajtakova, M., Petrasova, D., Pidanicova, A., Gallovicova, A., Blanarova, C., and Petrovicova, J. (2010). Serum levels of leptin, adiponectin, retinol binding protein 4 and leptin/adiponectin molar ratio as another possible marker of insulin resistance in obese. Bratisl. Lek. Listy 111, 212-215.

Tanaka, A., and Node, K. (2015). A novel cardioprotective mechanism of exogenous nitric oxide: inhibition of Rho-associated kinase activity. Hypertens Res. 38, 461-462. doi: 10.1038/hr.2015.61

Thomas, M., Gavrila, D., McCormick, M. L., Miller, F. J. Jr., Daugherty, A., Cassis, L. A., et al. (2006). Deletion of p47phox attenuates angiotensin IIinduced abdominal aortic aneurysm formation in apolipoprotein E-deficient mice. Circulation 114, 404-413. doi: 10.1161/CIRCULATIONAHA.105.607168
Touyz, R. M. (2003). The role of angiotensin II in regulating vascular structural and functional changes in hypertension. Curr. Hypertens. Rep. 5, 155-164. doi: $10.1007 / \mathrm{s} 11906-003-0073-2$

Touyz, R. M. (2005). Reactive oxygen species as mediators of calcium signaling by angiotensin II: implications in vascular physiology and pathophysiology. Antioxid. Redox Signal. 7, 1302-1314. doi: 10.1089/ars.2005.7.1302

Touyz, R. M., and Briones, A. M. (2011). Reactive oxygen species and vascular biology: implications in human hypertension. Hypertens Res. 34, 5-14. doi: 10.1038/hr.2010.201

Touyz, R. M., Yao, G., Quinn, M. T., Pagano, P. J., and Schiffrin, E. L. (2005). p47phox associates with the cytoskeleton through cortactin in human vascular smooth muscle cells: role in $\mathrm{NAD}(\mathrm{P}) \mathrm{H}$ oxidase regulation by angiotensin II. Arterioscler. Thromb. Vasc. Biol. 25, 512-518. doi: 10.1161/01.ATV.0000154141.66879.98

Tziros, C., and Freedman, J. E. (2006). The many antithrombotic actions of nitric oxide. Curr. Drug Targets 7, 1243-1251. doi: 10.2174/138945006778559111

Uchida, T., Shimizu, M., Sakai, Y., Nakano, T., Hara, K., Takebayashi, K., et al. (2008). Effects of losartan on serum total and high-molecular weight adiponectin concentrations in hypertensive patients with metabolic syndrome. Metabolism 57, 1278-1285. doi: 10.1016/j.metabol.2008.04.024

Ushio-Fukai, M., Zafari, A. M., Fukui, T., Ishizaka, N., and Griendling, K. K. (1996). p22phox is a critical component of the superoxidegenerating NADH/NADPH oxidase system and regulates angiotensin IIinduced hypertrophy in vascular smooth muscle cells. J. Biol. Chem. 271, 23317-23321. doi: 10.1074/jbc.271.38.23317

Van Heerebeek, L., Meischl, C., Stooker, W., Meijer, C. J., Niessen, H. W., and Roos, D. (2002). NADPH oxidase(s): new source(s) of reactive oxygen species in the vascular system? J. Clin. Pathol. 55, 561-568. doi: 10.1136/jcp.55. 8.561

Van Hove, C. E., Van Der Donckt, C., Herman, A. G., Bult, H., and Fransen, P. (2009). Vasodilator efficacy of nitric oxide depends on mechanisms of intracellular calcium mobilization in mouse aortic smooth muscle cells. Br. J. Pharmacol. 158, 920-930. doi: 10.1111/j.1476-5381.2009.00396.x

Wang, C., Li, L., Zhang, Z. G., Fan, D., Zhu, Y., and Wu, L. L. (2010). Globular adiponectin inhibits angiotensin II-induced nuclear factor kappaB activation through AMP-activated protein kinase in cardiac hypertrophy. J. Cell. Physiol. 222, 149-155. doi: 10.1002/jcp.21931

Yamakawa, T., Tanaka, S., Numaguchi, K., Yamakawa, Y., Motley, E. D., Ichihara, S., et al. (2000). Involvement of Rho-kinase in angiotensin II-induced hypertrophy of rat vascular smooth muscle cells. Hypertension 35, 313-318. doi: 10.1161/01.HYP.35.1.313

Yamauchi, T., and Kadowaki, T. (2013). Adiponectin receptor as a key player in healthy longevity and obesity-related diseases. Cell Metab. 17, 185-196. doi: 10.1016/j.cmet.2013.01.001

Yuan, F., Li, Y. N., Liu, Y. H., Yi, B., Tian, J. W., and Liu, F. Y. (2012). Adiponectin inhibits the generation of reactive oxygen species induced by high glucose and promotes endothelial NO synthase formation in human mesangial cells. Mol. Med. Rep. 6, 449-453. doi: 10.3892/mmr.2012.931

Zeidan, A., Gan, X. T., Thomas, A., and Karmazyn, M. (2014). Prevention of RhoA activation and cofilin-mediated actin polymerization mediates the antihypertrophic effect of adenosine receptor agonists in angiotensin II- and endothelin-1-treated cardiomyocytes. Mol. Cell. Biochem. 385, 239-248. doi: 10.1007/s11010-013-1832-2

Zeidan, A., Javadov, S., Chakrabarti, S., and Karmazyn, M. (2008). Leptin-induced cardiomyocyte hypertrophy involves selective caveolae and RhoA/ROCKdependent p38 MAPK translocation to nuclei. Cardiovasc. Res. 77, 64-72. doi: $10.1093 / \mathrm{cvr} / \mathrm{cvm} 020$

Zeidan, A., Javadov, S., and Karmazyn, M. (2006). Essential role of Rho/ROCKdependent processes and actin dynamics in mediating leptin-induced hypertrophy in rat neonatal ventricular myocytes. Cardiovasc. Res. 72, 101-111. doi: 10.1016/j.cardiores.2006.06.024

Zeidan, A., Nordstrom, I., Albinsson, S., Malmqvist, U., Sward, K., and Hellstrand, P. (2003). Stretch-induced contractile differentiation of vascular smooth muscle: sensitivity to actin polymerization inhibitors. Am. J. Physiol. Cell Physiol. 284, C1387-C1396. doi: 10.1152/ajpcell.00508.2002

Zeidan, A., Paylor, B., Steinhoff, K. J., Javadov, S., Rajapurohitam, V., Chakrabarti, S., et al. (2007). Actin cytoskeleton dynamics promotes leptin-induced vascular smooth muscle hypertrophy via RhoA/ROCK- 
and phosphatidylinositol 3-kinase/protein kinase B-dependent pathways. J. Pharmacol. Exp. Ther. 322, 1110-1116. doi: 10.1124/jpet.107. 122440

Zeidan, A., Purdham, D. M., Rajapurohitam, V., Javadov, S., Chakrabarti, S., and Karmazyn, M. (2005). Leptin induces vascular smooth muscle cell hypertrophy through angiotensin II- and endothelin-1-dependent mechanisms and mediates stretch-induced hypertrophy. J. Pharmacol. Exp. Ther. 315, 1075-1084. doi: 10.1124/jpet.105.091561

Zhang, Y., Griendling, K. K., Dikalova, A., Owens, G. K., and Taylor, W. R. (2005). Vascular hypertrophy in angiotensin II-induced hypertension is mediated by vascular smooth muscle cell-derived $\mathrm{H} 2 \mathrm{O} 2$. Hypertension 46, 732-737. doi: 10.1161/01.HYP.0000182660.74266.6d

Zhou, M. S., Schulman, I. H., and Raij, L. (2004). Nitric oxide, angiotensin II, and hypertension. Semin. Nephrol. 24, 366-378. doi: 10.1016/j.semnephrol.2004.04.008
Zhu, W., Cheng, K. K., Vanhoutte, P. M., Lam, K. S., and Xu, A. (2008). Vascular effects of adiponectin: molecular mechanisms and potential therapeutic intervention. Clin. Sci. (Lond.) 114, 361-374. doi: 10.1042/CS20070347

Conflict of Interest Statement: The authors declare that the research was conducted in the absence of any commercial or financial relationships that could be construed as a potential conflict of interest.

Copyright (c) 2016 Nour-Eldine, Ghantous, Zibara, Dib, Issaa, Itani, El-Zein and Zeidan. This is an open-access article distributed under the terms of the Creative Commons Attribution License (CC BY). The use, distribution or reproduction in other forums is permitted, provided the original author(s) or licensor are credited and that the original publication in this journal is cited, in accordance with accepted academic practice. No use, distribution or reproduction is permitted which does not comply with these terms. 